\title{
Development of Biofunctionalized Cellulose Acetate Nanoscaffolds for Heart Valve Tissue Engineering
}

\author{
Eirini Chainoglou1, Varvara Karagkiozaki1, Theodora Choli-Papadopoulou' ${ }^{2}$, \\ Charisios Mavromanolis ${ }^{1,3}$, Argiris Laskarakis ${ }^{1}$, Stergios Logothetidis ${ }^{1}$
}

\author{
${ }^{1}$ Nanomedicine Group, Department of Physics, Aristotle University of Thessaloniki, Thessaloniki, Greece \\ ${ }^{2}$ Department of Chemistry, Aristotle University of Thessaloniki, Thessaloniki, Greece \\ ${ }^{3}$ Cardio-Thoracic Surgery Clinic, General Hospital “G. PAPANIKOLAOU”, Exohi Thessaloniki, Greece \\ Email: eirini_xai@hotmail.com
}

How to cite this paper: Chainoglou, E., Karagkiozaki, V., Choli-Papadopoulou, T., Mavromanolis, C., Laskarakis, A. and Logothetidis, S. (2016) Development of Biofunctionalized Cellulose Acetate Nanoscaffolds for Heart Valve Tissue Engineering. World Journal of Nano Science and Engineering, 6, 129-152.

http://dx.doi.org/10.4236/wjnse.2016.64013

Received: October 2, 2016

Accepted: November 5, 2016

Published: November 8, 2016

Copyright $\odot 2016$ by authors and Scientific Research Publishing Inc. This work is licensed under the Creative Commons Attribution International License (CC BY 4.0).

http://creativecommons.org/licenses/by/4.0/

(c) (i) Open Access

\begin{abstract}
Currently-used mechanical and biological heart valve prostheses have a satisfactory short-term performance, but may exhibit several major drawbacks on the long-term. Mechanical prostheses, based on carbon, metallic and polymeric components, require permanent anticoagulation treatment, and their usage often leads to adverse reactions, e.g. thromboembolic complications and endocarditis. In recent years, there is a need for a heart valve prosthesis that can grow, repair and remodel. The concept of tissue engineering offers good prospects into the development of such a device. An ideal scaffold should mimic the structural and purposeful profile of materials found in the natural extracellular matrix (ECM) architecture. The goal of this study was to develop cellulose acetate scaffolds (CA) for valve tissue regeneration. After their thorough physicochemical and biological characterization, a biofunctionalization process was made to increase the cell proliferation. Especially, the surface of scaffolds was amplified with functional molecules, such as RGD peptides (Arg-Gly-Asp) and YIGSRG laminins (Tyrosine-Isoleucine-Glycine-Serine-Arginine-Glycine) which immobilized through biotin-streptavidin bond, the strongest non-covalent bond in nature. Last step was to successfully coat an aortic metallic valve with CA biofunctionallized nanoscaffolds and cultivate cells in order to create an anatomical structure comparable to the native valve. Promising results have been obtained with CA-based nanoscaffolds. We found that cells grown successfully on the biofunctionalized valve surface thereby scaffolds that resemble the native tissues, elaborated with bioactive factors such as RGD peptides and laminins not only make the valve's surface biocompatible but also they could promote endothyliazation of cardiac valves causing an anti-coagulant effect.
\end{abstract}




\section{Keywords}

Heart Valve Tissue Engineering, Cellulose Acetate, Scaffolds, Nanomaterials, Polymers, Atomic Force Microscopy

\section{Introduction}

Cardiovascular disease (CVD) represents a major worldwide health care issue. A considerable amount of the disease is represented by heart valve failures. The number of patients requiring heart valve replacement is estimated to triple from approximately 290,000 in 2003 to over 850,000 by 2050 [1] [2] [3]. The heart valve industry in the US is vibrant and healthy, enjoying a growth in the market of 5\% per year, selling roughly 300,000 valves worldwide [4]. As a result, the economic costs for the treatment and care of patients are estimated at several billion dollars [5]. Thus scientists try hard to develop a new type of heart valve that can potentially revolutionize the industry [6] and improve patient's lives. However, the current substitute heart valves have proven to be clinically successful over the short-term, but show several poignant long-term disadvantages [7] [8]. In particular, the tissue valves including bioprosthetic valves [porcine aortic valve or bovine pericardial xenograft], cadaveric allograft, or pulmonaryto-aortic autograft valves [9], are effective for a specific period and require replacement again. Additionally, xenogenous and allogenous biological heart valve prostheses evoke an immune reaction of the patient's organism, thrombosis and undergo degeneration, calcification and structural deterioration [10] [11] [12]. On the other hand, although the mechanical prostheses (mainly made of pyrolytic carbon combined with metallic and polymeric components) [1] are durable and for whole lifetime of the patient, they carry risks associated either with the valve itself, e.g. thrombus formation, thromboembolic complications, endocarditis that occurs predominantly on the surface of foreign materials, or risks related to permanent and long-lasting anticoagulation therapy, e.g. bleeding complications occurring at $1 \%$ patients per year [13]. Therefore, an alternative way to improve the quality of heart valve prostheses is to combine the present knowledge and construct bioartificial valves by tissue engineering. A tissue-engineered valve promises to be a living implant with a potential to grow and lasts a lifetime, like most native valves do [6]. Therefore, efforts are made to prepare bioartificial heart valves with an autologous biological component by tissue engineering [1]. The ideal valve prosthesis should be easily implantable, should develop a physiological hemodynamic performance without structural deterioration, and should be non-thrombogenic, nonimunogenic and silent in its performance [14]. For this purpose, scaffolds composed of synthetic materials, such as poly (lactic acid), poly (caprolactone), poly (4-hydroxybutyrate), hydrogels or natural polymers, e.g. collagen, elastin, fibrin or hyaluronic acid, have been seeded with autologous differentiated, progenitor or stem cells [1]. In recent years, a very promising natural polymer in the field of tissue engineering is cellulose acetate (CA). Cellulose acetate is derived from cellulose with chemical conversion 
[15], which is the most abundant, renewable, naturally occurring polysaccharide formed out of glucose-based repeat units, connected by 1,4-beta-glucosidic linkages [16]. It can be easily fabricated into nanofibrous structures by using the electrospinning method [17]. Electrospinning is a versatile and well-established technique broadly applied for the fabrication of nanofibrous meshes as scaffolds for tissue engineering applications. With recent developments in electrospinning, both synthetic and natural polymers can be produced as nanofibers with diameters ranging from tens to hundreds of nanometers with controlled morphology and function. Electrospun scaffolds exhibit a preferential and easy to modulate morphology due to their unique geometrical features which replicate many in vivo structures. The potential of these electrospun nanofibers in human healthcare applications is promising, for example in tissue/organ repair and regeneration, as vectors to deliver drugs and therapeutics, as biocompatible and biodegradable medical implant devices, in medical diagnostics and instrumentation, as protective fabrics against environmental and infectious agents in hospitals and general surroundings, and in cosmetic and dental applications [18] [19] [20] [21]. Moreover, electrospinning parameters such as, solvent composition, polymer concentration and flow rate, impact the structure of CA scaffolds. Solvent selection along with flow rate strongly influenced the cellulose acetate fiber size, size distribution, and fiber geometry [22] [23]. Electrospun CA nanofibers have found miscellaneous applications such as in immobilization of bioactive substances, cell culture, tissue engineering, and optical device/biosensor application [24]. Cellulose acetate scaffolds and regenerated cellulose scaffolds promote cardiac cell growth; enhance cell connectivity and electrical functionality. Also, biodegradability can be controlled by hydrolysis, de-acetylization of CA and cytocompatibility enzyme action, with glucose as a final product [16]. Additionally, the CA-based nanofibrous scaffolds improve their integrity by blending with other polymers like PBA [poly(butyl acrylate)] [25]. In vitro growth of cardiac cells and tissuelike cardiac constructs for physiomics type of research could benefit from the versatility and accessibility of cellulose scaffolds; their use for tissue regeneration should also be considered [16]. Polymeric and metallic materials are used extensively in permanently implanted cardiovascular devices and devices that make temporary but often prolonged contact with body fluids and tissues. A recent study examines the evolving plasma treatment technology facilitating the biofunctionalization of polymeric and metallic implantable cardiovascular materials [26]. Moreover, surface modification of RGD peptides onto acellularized porcine aortic valve helps to promote cell adhesion [27]. Previous biomedical applications of cellulose-derived materials suggest their potential use as general supporting and guiding structures for cell culture and possibly for reparative tissue engineering [16]. The aim of the present study was to develop and characterize CA-based scaffolds as coating in aortic heart valves. The ultimate goal was to create a biomimetic nanofibrous environment which simulates the extracellular matrix (ECM) of native cardiac tissues and thus promotes cell adhesion and proliferation in order to avoid heart valve thrombosis. Producing nanofibrous scaffolds of biodegradable polymer CA was accomplished by the Electrospray Deposition method. Electrospun 
CA nanofibers were physiochemical, structural and morphological characterized. The Atomic Force Microscopy (AFM) was applied to study the surface nanotopography of the scaffolds and the Scanning Electron Microscopy (SEM) was used in order to study the topography and morphology of the scaffolds. Concomitantly, we studied wettability of the samples with contact angle measurements and degradation rates of the CA scaffolds in a 2 month period. In addition, MTT assay along with imaging techniques were used to evaluate the cell viability. Specifically, both direct MTT assay at intervals of 24 hours, 3 days and 7 days and indirect MTT assay in a 24 hour period were taken place. Moreover, the cells were stained with methylene Blue dye and observed by optical microscopy. Afterwards, RGD peptides and laminins were immobilized on the surface of CA scaffolds in order to mimic the real exterior environment of the cells and promote cell proliferation. Finally, the biofunctionalized CA scaffolds were deposited on the surface of an aortic heart valve which was made of pyrolytic carbon for avoidance of heart valve thrombosis.

\section{Materials and Methods}

\subsection{Materials}

Acetone (99.9\%, Sigma-Aldrich), Dimethylacetamide (DMAc 99.9\%, Sigma-Aldrich) and vacuumed dried cellulose acetate $(\mathrm{CA}, \mathrm{Mn}=30,000,39.8 \%$ acetyl groups, Sigma Aldrich). All solutions were used without further purification and all solutions were prepared by deionised water.

\subsection{Methods}

\subsubsection{Scaffold Fabrication with Electrospray Deposition System}

The nanofibrous CA scaffolds for cell growth were fabricated by electrospinning through the electrostatic spray deposition (ESD) method, (Esprayer ES-2000S, Fuence, Japan) onto aluminum foil and glass substrates. For fabrication of the polymeric solutions, two solutions of cellulose acetate were prepared with a total concentration of 16 $\mathrm{wt} \%$ and $20 \mathrm{wt} \%$ in a solvent mixture of Acetone: DMA (2:1). The number of syringes were used for fabrication were 1 or 2 . The solution was electrospun from a $5 \mathrm{~mL}$ syringe (or two syringes) with 24 or 21 gauge needles and mass flow rate of $10-15 \mu \mathrm{L} / \mathrm{min}$. A high voltage $(25 \mathrm{kV})$ was applied to the tip of the needle when the fluid jet was ejected. The distance between the needle and the moving collector in the XY stage, was set at $200 \mathrm{~mm}$. The glass substrates were cleaned prior to electrospinning with isopropanol and methanol and blow-dried using N2 flow. Each fabricated film was left overnight to allow the evaporation of any residual solvents.

\subsubsection{Physicochemical Characterization}

1) Scanning electron microscopy (SEM)

The cells were fixed in $500 \mu \mathrm{l}$ of $2.5 \%$ glutaraldehyde solution in PBS for $20 \mathrm{~min}$ at room temperature and dehydrated with a series of increasing concentration ethanol solutions (70\%, 90\% and 100\% ethanol, $30 \mathrm{~min}$ in each). After ethanol dehydration, the 
morphological analysis of the PCL scaffolds was carried out by using SEM (NEON40, Carl Zeiss).

2) Atomic force microscopy (AFM)

Atomic force microscopy, AFM (AFM Solver, NT-MDT) was used to determine surface nanotopography and roughness of the cellulose acetate scaffolds. AFM is a very high-resolution type of scanning probe microscope, with demonstrated resolution of fractions of a nanometer, ideal for the imaging of biological samples due to its nondestructive performance. It can also provide size characterization in all three spatial dimensions, because it provides direct information about the height as well as lateral dimensions of the samples.

3) Contact angle measurements

Static contact angle measurements using water (Contact angle-surface tensionmeter CAM200, KSV Instruments Ltd) for the electrospun CA scaffolds were performed to study and compare the effect of the different CA fibers (CA concentration, needle size and number of syringes) on the surface hydrophilicity. At least six different measurements on the nanofibrous surfaces were obtained and the average values for contact angles were calculated. The maximum error in the contact angle measurement did not exceed $\pm 3 \%$.

4) Biodegradation study

We studied the degradation of cellulose acetate fibers in a period of 2 months (the time periods used are 3, 7, 14,30, 45 and 60 days). The substrate of the samples was aluminium foil and they were cut into dimensions $10 \mathrm{x} 10 \mathrm{~cm}$. Samples were weighed on a balance precision before and after degradation, and the results were recorded. Also samples were imaged with SEM and then treated with the Image J program in order to calculate the length of the fiber diameter. In each picture (magnification $\times 4000$ ) were counted 25 different fibers.

\subsubsection{Biological Characterization}

1) Direct MTT assay

MTT assay (Sigma-Aldrich, Germany) was used to evaluate the cell viability. The cells used in this study were mouse fibroblasts L929 and were kindly offered from the Department of Biochemistry of the Aristotle University of Thessaloniki. The cell line was cultured in Medium 199 (Gibco, Life Technologies, Carlsbad, CA), containing 5\% fetal bovine serum, ascorbic acid, and gentamicin at $37^{\circ} \mathrm{C}$, in a humidified atmosphere of $5 \% \mathrm{CO}_{2}$ in air. In a similar manner as described in [28], the cell growth was stopped after 1 day, 3 days and 1 week. After each time point, the cells were incubated with a tenth of the medium of the bromide in $5 \% \mathrm{CO}_{2}\left(37^{\circ} \mathrm{C}, 2 \mathrm{~h}\right)$ to allow the formation of water-insoluble formazan crystals. The optical densities (O.D.) of the solutions were read with a spectrophotometer, at the wavelength of $570 \mathrm{~nm}$ with respect to the reference wavelength of $690 \mathrm{~nm}$. Data $(n=3)$ were presented as means of O.D. values as well as normalized according to the control and presented as\% cell viability.

2) Indirect MTT assay

Additionally, an indirect MTT assay was taken place, on which the extracts of cellu- 
lose acetate nanoscaffolds hydrolyzed from the experiment of degradation (they were isolated from six time periods 3, 7, 14, 30, 45 and 60 days), deposited onto L929s cells and the toxicity was calculated based on optical density (O.D.) just described in direct MTT assay.

\subsubsection{Cell Imaging}

Once fibroblasts were seeded onto either unmodified or surface-modified nanofibrous scaffolds, cellular morphology and cell attachment were observed after 1, 3 and 7 days. Cells were fixed, after the predetermined time periods, in $4 \%$ formaldehyde/PBS, at $\mathrm{rt}$ for 20 min, permeabilized with PBS and incubated with methylene blue (blue fluorescence) at $\mathrm{rt}$ for $30 \mathrm{~min}$. The cell surface was observed with an optical microscope (Carl Zeiss, Germany).

\subsubsection{Biofunctionalization Study}

\section{1) Biofunctionalization process}

The surface treatment was used in cellulose acetate samples in order to bind molecules on their surface, such as RGD (Arg-Gly-Asp) peptides and YIGSRG laminins [Tyrosine-Isoleucine-Glycine-Serine-Arginine-Glycine. The creation of free amino groups presupposes the existence or creation of free hydroxyl groups $(-\mathrm{OH})$. Surface preparation and immobilization of RGD peptides and YIGSRG laminins: Carbon surfaces with sp2 bonds are subject to short exposure to UV. Epistaxis $350-400 \mathrm{ml}$ $\mathrm{PEI} / \mathrm{Na}_{2} \mathrm{CO}_{3}, \mathrm{pH}=8.2$ and stay overnight in the dark (cover with foil and place in a closed room). This step ensures the interaction between the surface and the solution in the dark, overnight. In this reaction, amino groups are introduced onto the surface to be studied. After about 12 hours spent in the darkroom surfaces washed with excess deionized water. This is achieved by successive dips into new wells containing $1 \mathrm{ml} \mathrm{H}_{2} \mathrm{O}$ so as to remove excess PEI solution $/ \mathrm{Na}_{2} \mathrm{CO}_{3}, \mathrm{pH}=8.2$. Next, performed preparation of a mixture of $50 \mathrm{mg} / \mathrm{ml}$ of polyethylene glycol (PolyEthyleneGlycol, PEG) (mPEG-SPA, MW 5.000) and $5 \mathrm{ng} / \mathrm{ml}$ biotinylated PEG (biotin-PEG-NHS, MW 3.400), in $50 \mathrm{mM}$ $\mathrm{Na}_{2} \mathrm{CO}_{3}$ (1:107). PEG, in which a very small percentage are biotinylated, as illustrated above, and coupled to the N-hydroxyester of succinimide (N-HydroxySuccinimidyl ester, NHS-ester). This ester is reacted with amino groups to form a covalent bond. The above solution of biotinylated PEG (b-PEG, biotin-PEG-NHS), and non-biotinylated PEG (mPEG-SPA) at 1: 107 were dropped on the surface and allowed to react with the amino groups of 3 - 5 hours dark at room temperature. The process followed by washing the surface by successive immersions-in the same manner as previously; in deionized water to remove excess b-PEG-PEG solution. Then, washing followed by drying of the surfaces for $1 \mathrm{hr}$ at $37^{\circ} \mathrm{C}$. At this stage the modified surfaces can be stored in glass plates at $4^{\circ} \mathrm{C}$. Add of streptavidin $2 \mathrm{mg} / \mathrm{ml}$ in $50 \mathrm{mM} \mathrm{Na}_{2} \mathrm{CO}_{3}$. Streptavidin has four binding sites for biotin. So binds to biotin surface but still has free binding sites for other biotin molecules in vivo conjugated with biotinylated peptides proteins. In these positions could be captured, very special and with the same orientation, biotinylated proteins to a specific location. The streptavidin solution remains in contact with the 
surface for about 20 minutes. Here are 20 washes the surface with $50 \mathrm{mM} \mathrm{Na} \mathrm{CO}_{3}$ and 10 washes with the buffer dialysis [20 Mm Hepes- $\mathrm{KOH}, \mathrm{pH}=7.6,6 \mathrm{Mm}\left(\mathrm{CH}_{3} \mathrm{COO}\right) 2$ $\mathrm{Mg}, 30 \mathrm{Mm} \mathrm{CH}_{3} \mathrm{COONH}_{4}$ and $4 \mathrm{Mm}$ beta merkaptoaithamolis, Tico buffer]. Then epistazontai 40 nM GFP in Tico buffer were dropped on the surface and kept for 15 - 20 minutes. Subsequently, took place the binding of biotinylated RGD peptides and biotinylated laminin in the cellulose acetate scaffold surface [29].

2) CA scaffolds deposition on aortic metallic heart valve

The CA scaffold was deposited on the surface of aortic valve from pyrolytic carbon by ESD. Then, the samples were biofunctionalized by adding RGD peptide and laminins as described previously and then L929s cells were cultured on the surface of the valve for periods of 1 and 3 days. Lastly, the nanofiber based valve was imaged by SEM.

\section{Results}

\subsection{Surface Nanotopography and Structural Properties of CA-Based Scaffolds}

The CA nanofibrous scaffolds were prepared by electrospinning, using different system parameters such as the CA concentration $16 \% \mathrm{w} / \mathrm{v}$ and $20 \% \mathrm{w} / \mathrm{v}$, the needle size 21 gauge or 24 gauge and the number of the syringes one or two. Samples showed well formed fibers and the acetone/DMAc solvent system was found suitable to produce fibers. A morphological and surface characterization of the CA scaffolds was performed in order to find the optimum synthetic conditions for their use in heart valve tissue engineering and the SEM images of the scaffolds are depicted in Figures 1 (a)-(f). Concomitantly, SEM images were processed with the image J software, so as to estimate the length of the diameter of the fiber. In each sample was counted 25 CA fibers. Comparing the results of the six samples we observed that samples with $24 \mathrm{~g}$ needle create fibers with smaller diameter than those with $21 \mathrm{~g}$ needle while samples which were created with 2 syringes have almost double amount of fibers than those with 1 syringe. Additionally, samples with $20 \% \mathrm{w} / \mathrm{v}$ concentration of CA produces higher fiber's diameter range than those with $16 \%$ w/v CA concentration (Table 1). AFM has been a widely used technique for the observation of biomaterials at the atomic scale. Thus, it was used in order to determine the topographical features and roughness of the engineered scaffolds. The surface roughness parameters of the electrospun CA scaffolds are summarized in Table 2, while the obtained topographies of the samples are presented in Figures $1(\mathrm{~g})-(1)$.

\subsection{Wettability}

Contact angle analysis provides information on the hydrophobicity or hydrophilicity of materials. Table 2 shows the values of water contact angle measurements of the CA surfaces. It was found that the sample $16 \% \mathrm{w} / \mathrm{v}$ produced by 1 syringe with $21 \mathrm{G}$ needle shows the maximum hydrophobicity and the sample $20 \% \mathrm{w} / \mathrm{v}$ produced by 1 syringe with $24 \mathrm{G}$ needle shows the maximum hydrophilicity. We also observed that the samples with $21 \mathrm{G}$ needle exhibit a higher hydrophobicity compared with corresponding 
Table 1. Parameters of electrospinning that effect fibers formation.

\begin{tabular}{cccccccccc}
\hline $\begin{array}{c}\text { Solvent } \\
\text { system }(2: 1)\end{array}$ & $\begin{array}{c}\text { Concentration } \\
(\% \mathrm{w} / \mathrm{v})\end{array}$ & $\begin{array}{c}\text { Voltage } \\
(\mathrm{kV})\end{array}$ & $\begin{array}{c}\text { Flow rate } \\
(\mu \mathrm{l} / \mathrm{min})\end{array}$ & $\begin{array}{c}\text { Throw } \\
\text { distance }(\mathrm{cm})\end{array}$ & $\begin{array}{c}\text { Needle ID } \\
(\text { Gauge })\end{array}$ & Syringe & $\begin{array}{c}\text { Pattern } \\
\text { Relevant } \\
\text { findings }\end{array}$ & $\begin{array}{c}\text { Range of } \\
\text { fiber's }(\mu \mathrm{m})\end{array}$ \\
\hline Acetone/DMAc & $16 \%$ & 25 & 10 & 200 & $21 \mathrm{G}$ & 1 & Biospiral & Fibers & $0.39 \pm 2.6$ \\
Acetone/DMAc & $16 \%$ & 25 & 10 & 200 & $24 \mathrm{G}$ & 1 & Biospiral & Fibers & $0.2 \pm 0.9$ \\
Acetone/DMAc & $16 \%$ & 25 & 10 & 200 & $21 \mathrm{G}$ & 2 & Biospiral & Fibers & $0.79 \pm 5$ \\
Acetone/DMAc & $16 \%$ & 25 & 10 & 200 & $24 \mathrm{G}$ & 2 & Biospiral & Fibers & $0.28 \pm 3.79$ \\
Acetone/DMAc & $20 \%$ & 25 & 10 & 200 & $21 \mathrm{G}$ & 1 & Biospiral & Fibers & $0.44 \pm 4.65$ \\
Acetone/DMAc & $20 \%$ & 25 & 10 & 200 & $24 \mathrm{G}$ & 1 & Biospiral & Fibers & $0.3 \pm 1.74$ \\
\hline
\end{tabular}

(a) 16\%_1S_21G

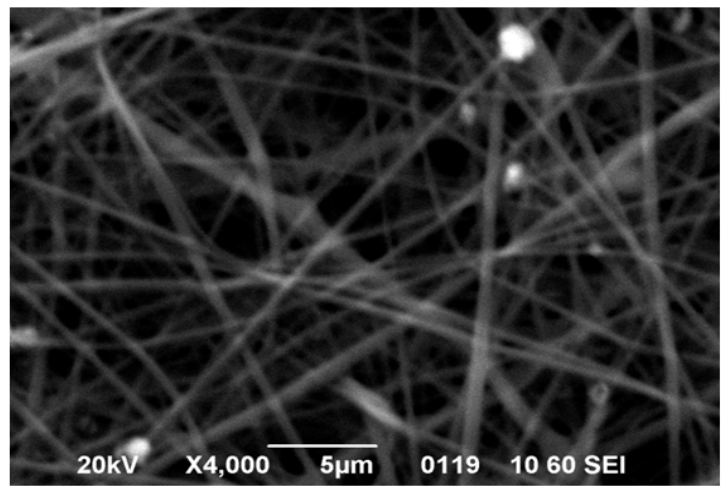

(c) $16 \% \_2 S \_21 G$

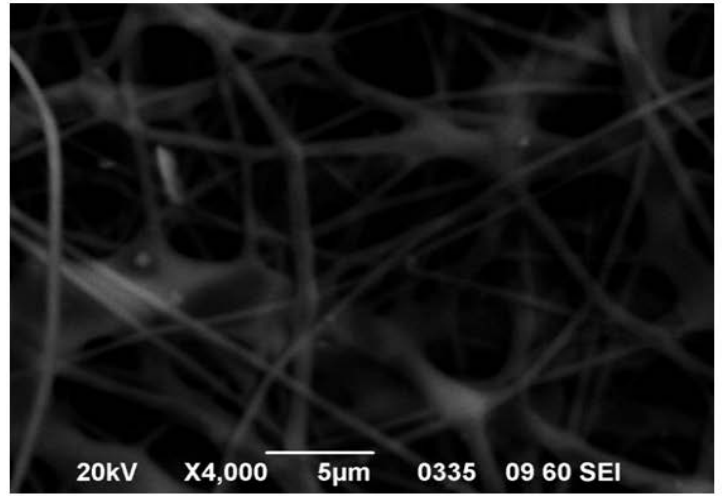

(e) 20\%_1S_21G

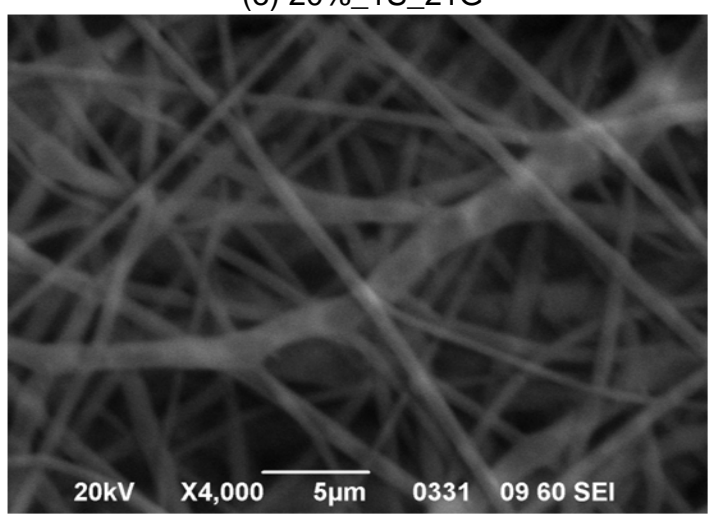

(b) $16 \% \_1 S \_24 G$

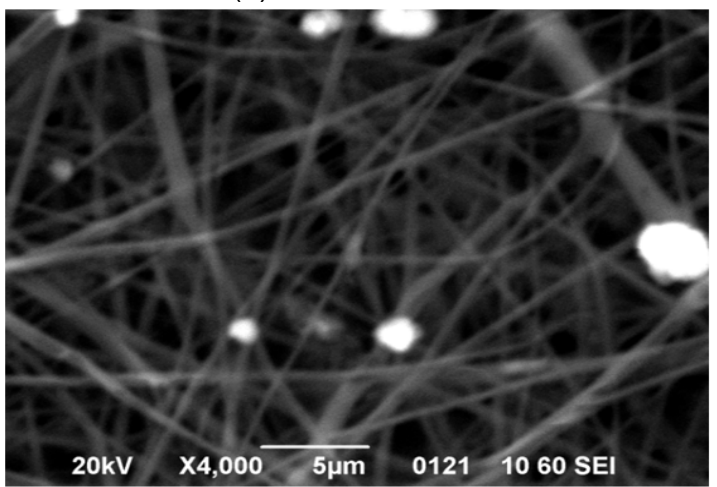

(d) $16 \%$ 2S_24G

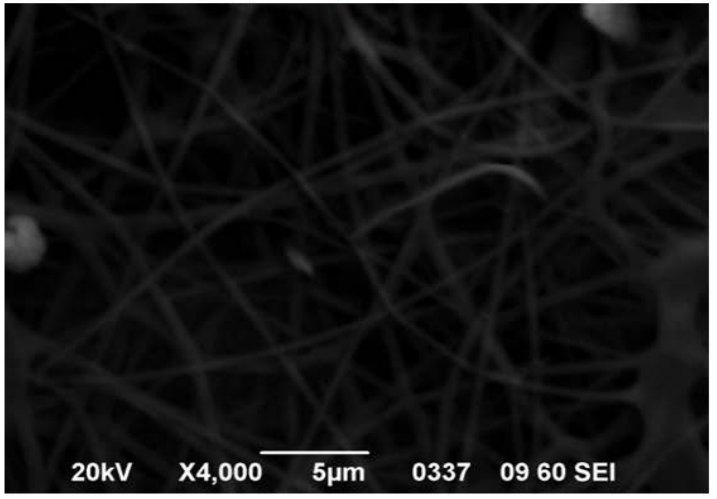

(f) $20 \% \_1 S \_24 G$

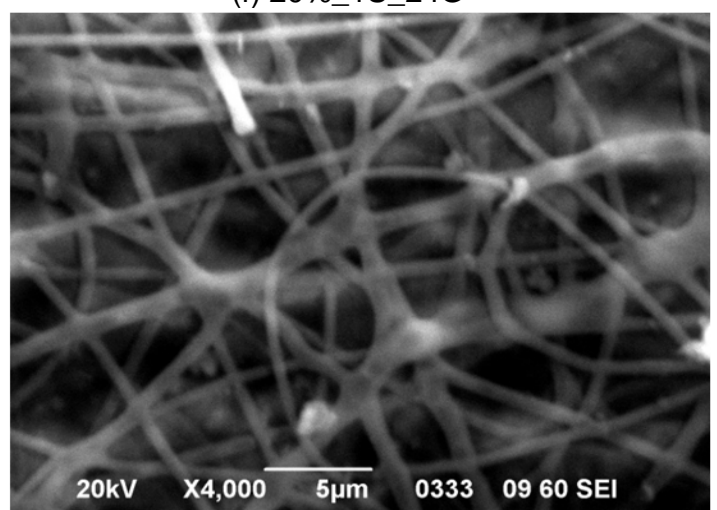


(g) $16 \% \_1 S \_21 G$

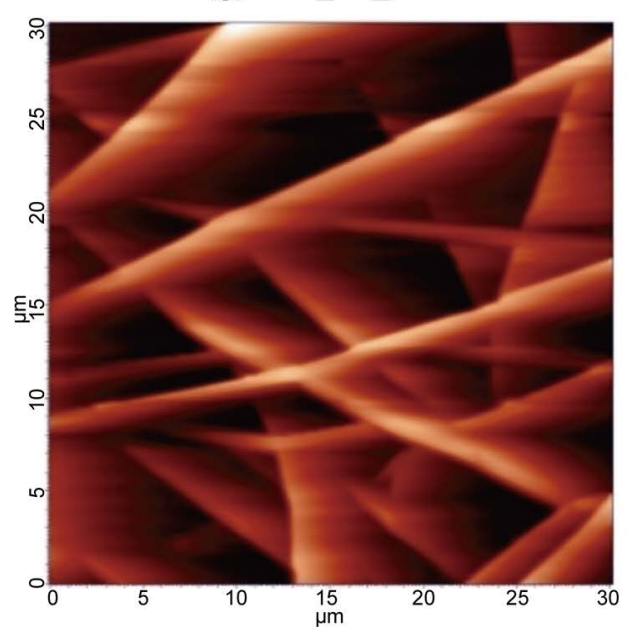

(i) 16\%_2S_21G

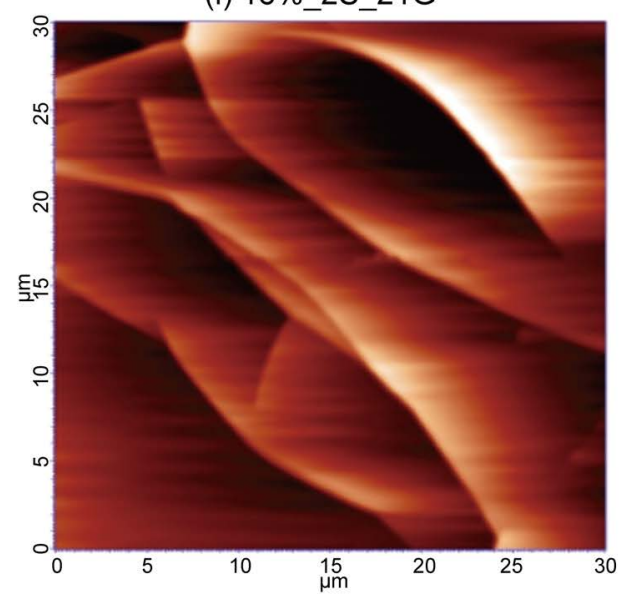

(k) $20 \%$ 1S_21G

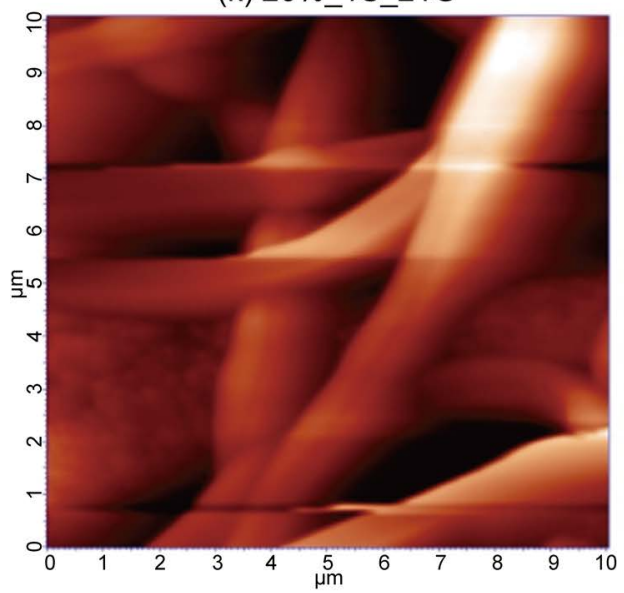

(h) $16 \%$ _1S_24G
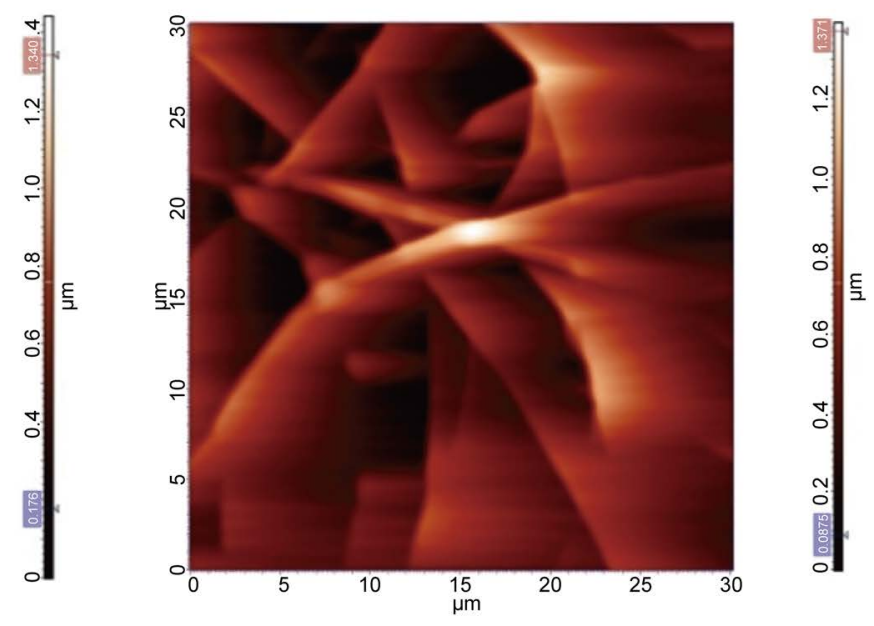

(j) $16 \% \_2 S \_24 G$
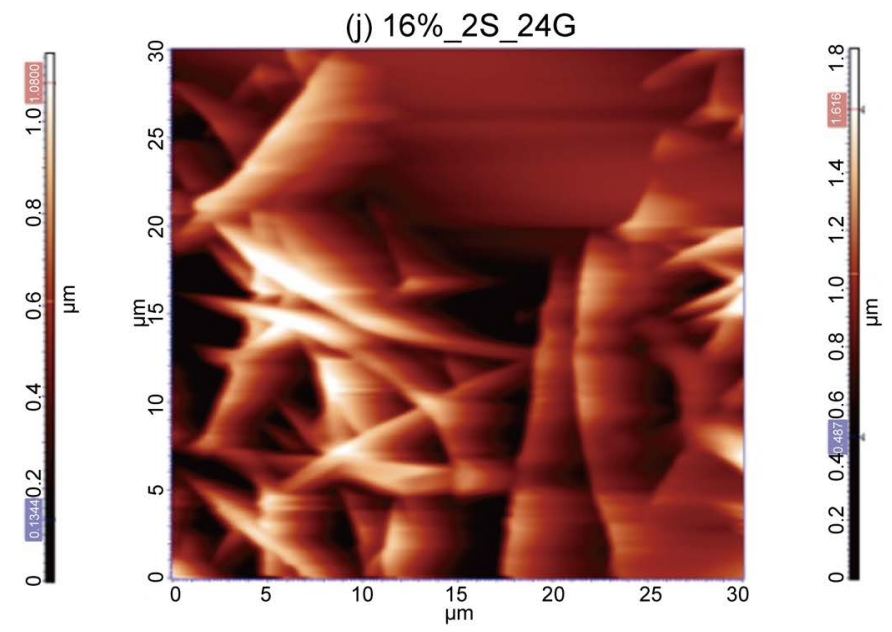

(I) $20 \%$ _1S_24G
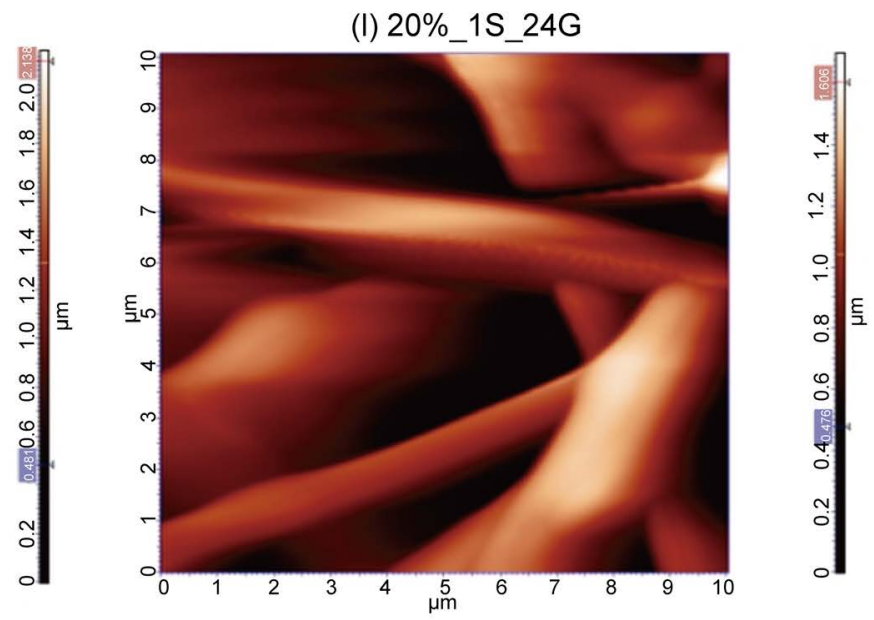

Figure 1. (a)-(f): Images by Scanning Electron Microscopy (SEM) from cellulose acetate scaffold. Solvents:Acetone/ DMAc 2:1, Substrate: al. foil. Zoom: $\times 4.000 \mathrm{~mm}$. (g)-(l): AFM images. Height pictures (a) (g): 16\%_1S_21G, (b) (h): 16\%_1S_24G, (c) (i): 16\%_2S_21G, (d) (j): 16\%_2S_24G, (e) (k): 20\%_1S_21G and (f) (l): 20\%_1S_24G. (\% w/v): CA concentration, G: needle size, S: number of syringes. 
Table 2. Surface characteristics from AFM analysis and water contact angle measurements for the CA nanofibrous scaffolds.

\begin{tabular}{cccc}
\hline CA-based scaffolds & $\begin{array}{c}\text { Peaak-to-peak, } \\
\mathrm{S}_{\mathrm{y}}(\mathrm{nm})\end{array}$ & $\begin{array}{c}\text { Root mean square, } \\
\mathrm{S}_{\mathrm{q}}(\mathrm{nm})\end{array}$ & $\begin{array}{c}\text { Contact angle } \\
\text { (degrees) }\end{array}$ \\
\hline 16\%_1S_21G & 1109.52 & 194.27 & 128.87 \\
16\%_1S_24G & 1196.17 & 229.14 & 91.16 \\
16\%_2S_21G & 877.975 & 174.88 & 106.45 \\
16\%_2S_24G & 2310.28 & 414.26 & 81.92 \\
20\%_1S_21G & 2178.15 & 337.68 & 87.42 \\
20\%_1S_24G & 1698.42 & 258.03 & 79.06 \\
\hline
\end{tabular}

samples (CA concentration and number of syringes) with 24G needle.

\subsection{Biodegradability}

CA-based scaffolds not only should have ideal morphological, structural and mechanical properties but also must present good rate of biodegradability in order to be suitable for a tissue engineering process. Scaffolds degradation comprises the hydrolysis and de-acetylization of the polymer. CA scaffolds were placed in cell's medium solution for 2 months. The experiment was divided into six periods (3, 7, 14, 30, 45 and 60 days) during which the scaffolds had been checked for their degradability. It was found that the samples with the largest cellulose acetate concentration, $20 \% \mathrm{w} / \mathrm{v}$ are heavier than the ones with $16 \% \mathrm{w} / \mathrm{v}$, as you can observe in Figure 2. When the $21 \mathrm{G}$ needle was used in electrospinning, in 14 days the samples the samples $16 \% \mathrm{w} / \mathrm{v}$ and $20 \% \mathrm{w} / \mathrm{v}$ had the highest weight and then during the rest of the study reduced weight due to their degradation. At 45 days observed for both concentrations, a slight increase in weight of the samples which then decreases (Figure $2(\mathrm{a})$ ). The sample $16 \% \mathrm{w} / \mathrm{v}$ produced by 2 syringes had less weight compared to the sample with the same concentration, but produced by one needle. On the other hand, in the case of the samples produced by $24 \mathrm{G}$ needle, it was observed that at 7 days the sample $16 \% \mathrm{w} / \mathrm{v}$ showed the highest weight and then during the rest of the study reduced weight due to their degradation. At 14 days the $20 \% \mathrm{w} / \mathrm{v}$ sample showed higher weight and then until the end of the study, it reduced weight due to degradation as well (Figure 2(b)). The sample 16\% w/v produced by 2 syringes, was found to have less weight compared to the sample with the same concentration, but produced by one needle. Also, the sample developed with $24 \mathrm{G}$ needle exhibited smaller diameter fibers compared to samples with $21 \mathrm{G}$ as presented in Figure 2(c). In this case where the concentration is the same, we observe that samples with $24 \mathrm{G}$ needle size are heavier compared to the samples with $21 \mathrm{G}$. Also, in each period of degradation study samples were studied by SEM, so as to examine their topography during degradation. From the images of CA scaffolds it was observed alteration in the structure of the fibers in all samples as the days of degradation went on. Additionally, the fibers in 60 days of degradation were presented thinner (i.e., smaller diameter) as compared to 0 days of degradation (Figure 3 ). 

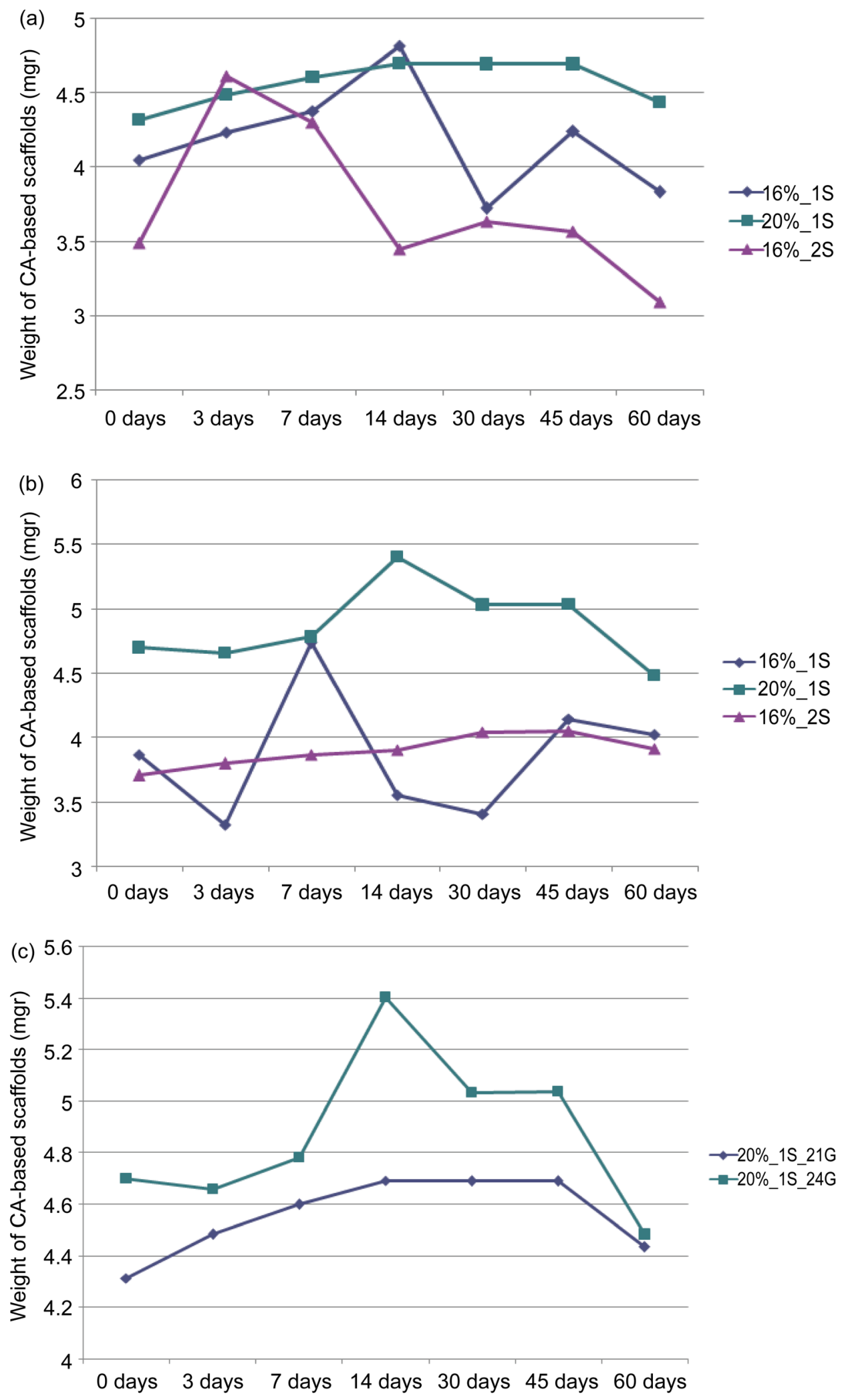

Figure 2. This diagram shows the CA samples having (a) needle size 21G (b), needle size $24 \mathrm{G}$ needle (c) concentration $20 \% \mathrm{w} / \mathrm{v}$. 

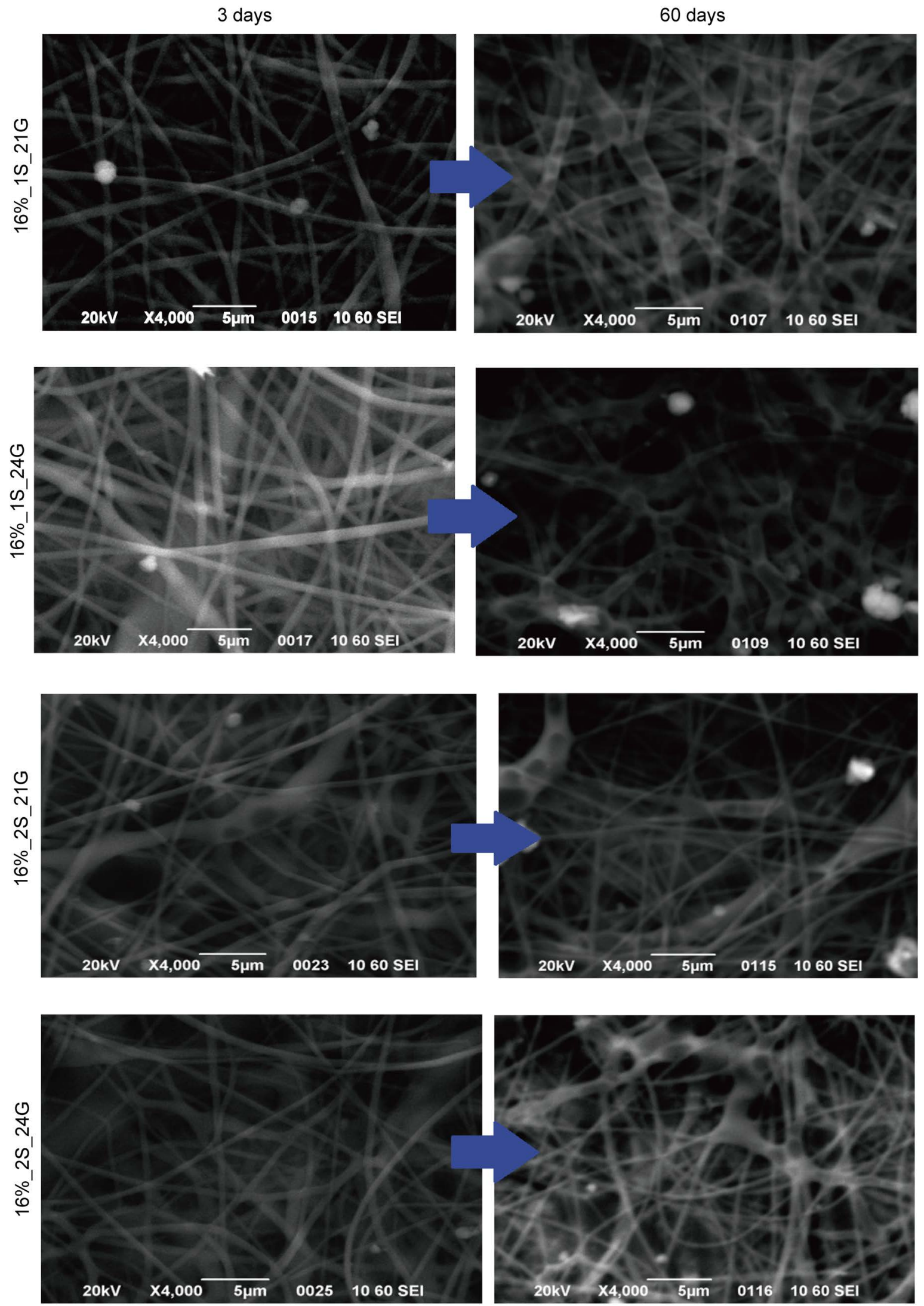

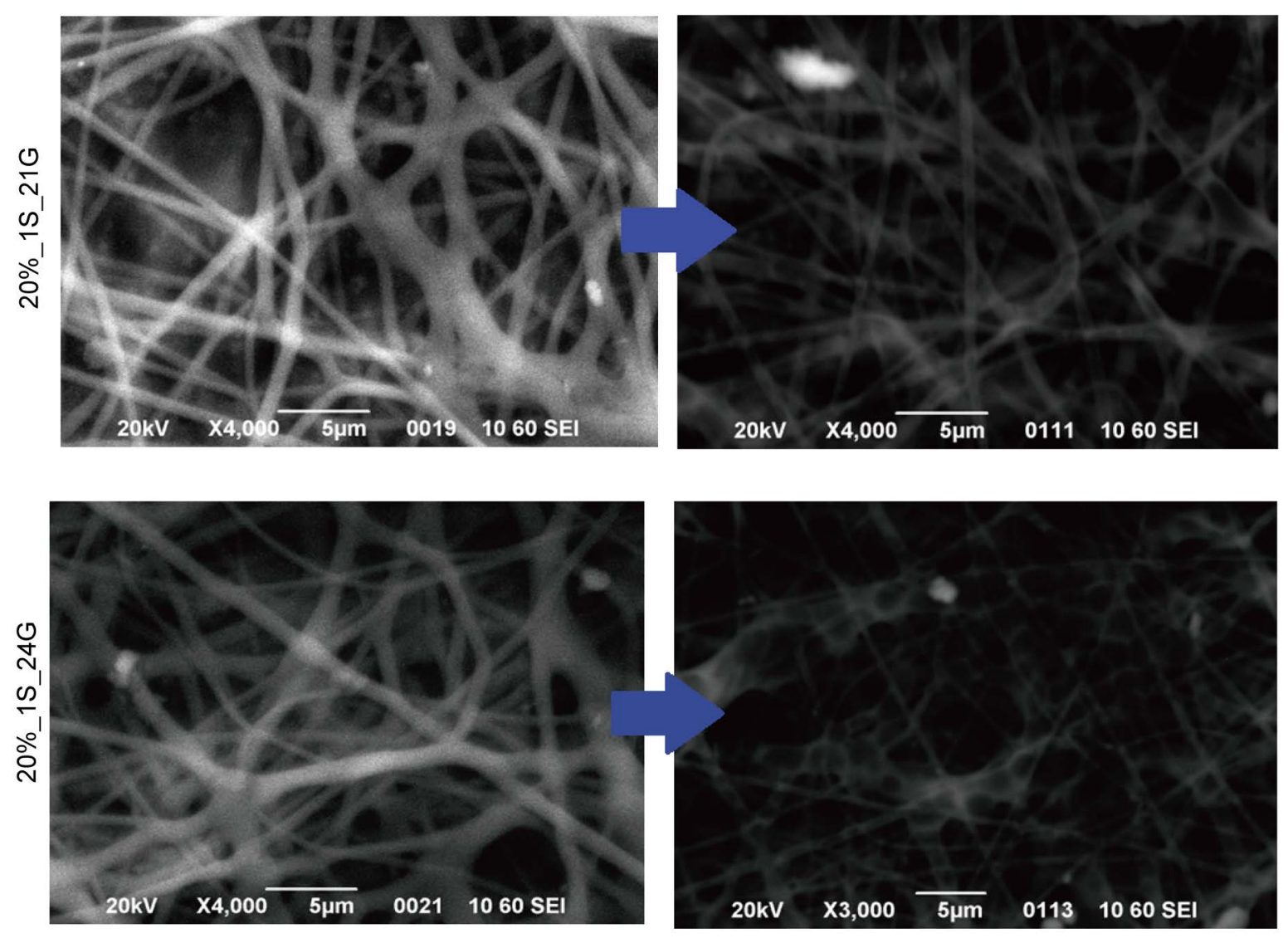

Figure 3. Images by Scanning Electron Microscopy (SEM) of cellulose acetate scaffold samples. Degradation of fibers in a range of time from 3 days to 60 days.

Furthermore, we studied the reduction of the diameter of the fibers in the six periods of the degradation study. More precisely, we calculated the diameter of 25 different fibers in ach SEM image, using image J software. The results are shown in Table 3 and Figure 4. It was found that in all samples, as the days went on, the diameter of the CA fibers decreases during the time.

\subsection{Cytotoxicity}

The MTT results which derived from the cytotoxicity levels of all the samples in direct contact with the L929s are given in Figure 5. According to the findings, all the fabricated scaffolds were found to be cytocompatible after a period of seven days and exhibited cell viability levels similar to those of the control group. Also, the sample with $20 \% \mathrm{w} / \mathrm{v}$ CA concentration, produced by the $24 \mathrm{G}$ needle and 1 syringe has shown the best cell viability levels. This effect is reinforced by the SEM images as well in Figure 6 . Additionally, it was found that samples with 2 syringes do not show strong cell proliferation in comparison with the sample produced by 1 syringe. Cells, particularly at 3 and 7 days were exhibited protrusions begging from the cell body (lamellipodia) and extending to filopodia. These findings are indicative of cell migration, sensing and interaction with the biomaterial. 
Table 3. Estimation of averange of fiber's diameter in the range of 2 months of degradation.

\begin{tabular}{cccccccc}
\hline \multirow{2}{*}{$\begin{array}{c}\text { CA-based } \\
\text { scaffolds }\end{array}$} & \multicolumn{7}{c}{ Average of fiber's diameter $(\mu \mathrm{m})$} \\
\cline { 2 - 7 } & 0 days & 3 days & 7 days & 14 days & 30 days & 45 days & 60 days \\
\hline 16\%_1s_21G & 0.906 & 0.643 & 0.560 & 0.74 & 0.488 & 0.478 & 0.768 \\
16\%_1s_24G & 0.764 & 0.874 & 0.565 & 0.596 & 0.680 & 0.5 & 0.837 \\
20\%_1s_21G & 2.089 & 0.952 & 0.906 & 0.673 & 0.86 & 0.752 & 0.695 \\
20\%_1s_24G & 0.9 & 1.062 & 1.304 & 0.887 & 0.779 & 0.228 & 0.513 \\
16\%_2s_21G & 1.43 & 0.663 & 0.549 & 0.5 & 0.547 & 0.543 & 0.478 \\
16\%_2s_24G & 1.07 & 0.528 & 0.590 & 1.072 & 0.615 & 0.68 & 0.492 \\
\hline
\end{tabular}

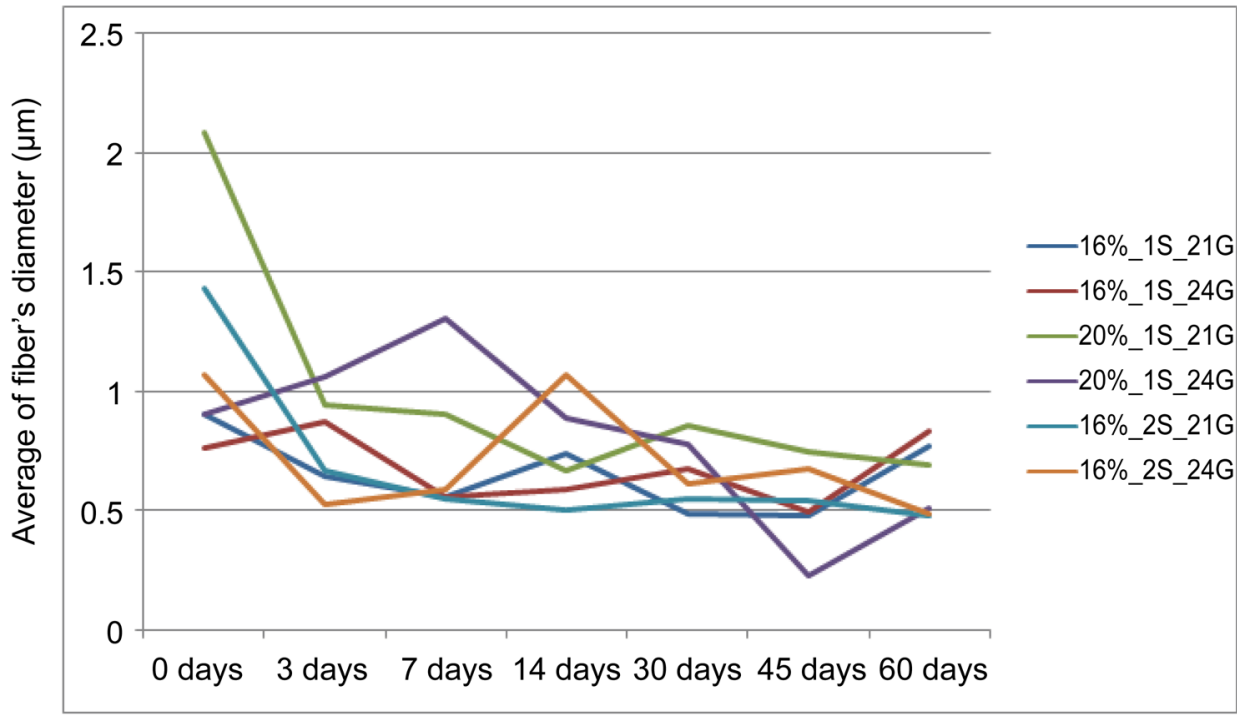

Figure 4. Average of fiber's diameter in the range of 2 months of degradation measured in all samples.

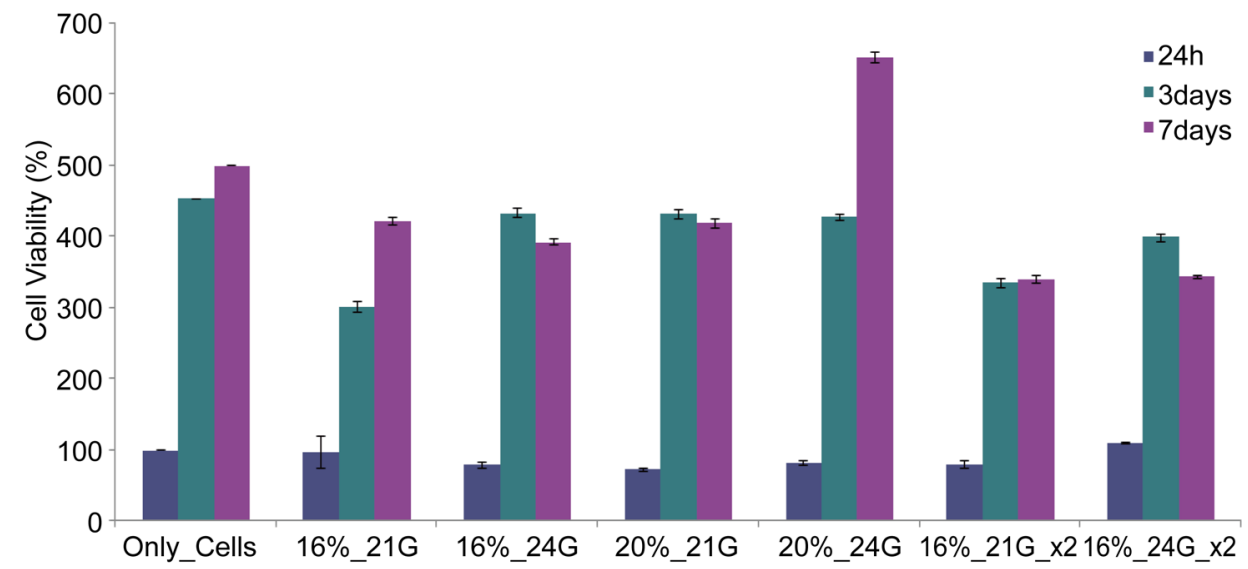

Figure 5. Diagram of optical density OD at $570 \mathrm{~nm}$ (cell viability\%) after direct MTT assay, using L929s cell line onto foil substrate for three times ( 24 h, 3 days and 7 days). Solvents:Acetone/ DMA, 2:1. 

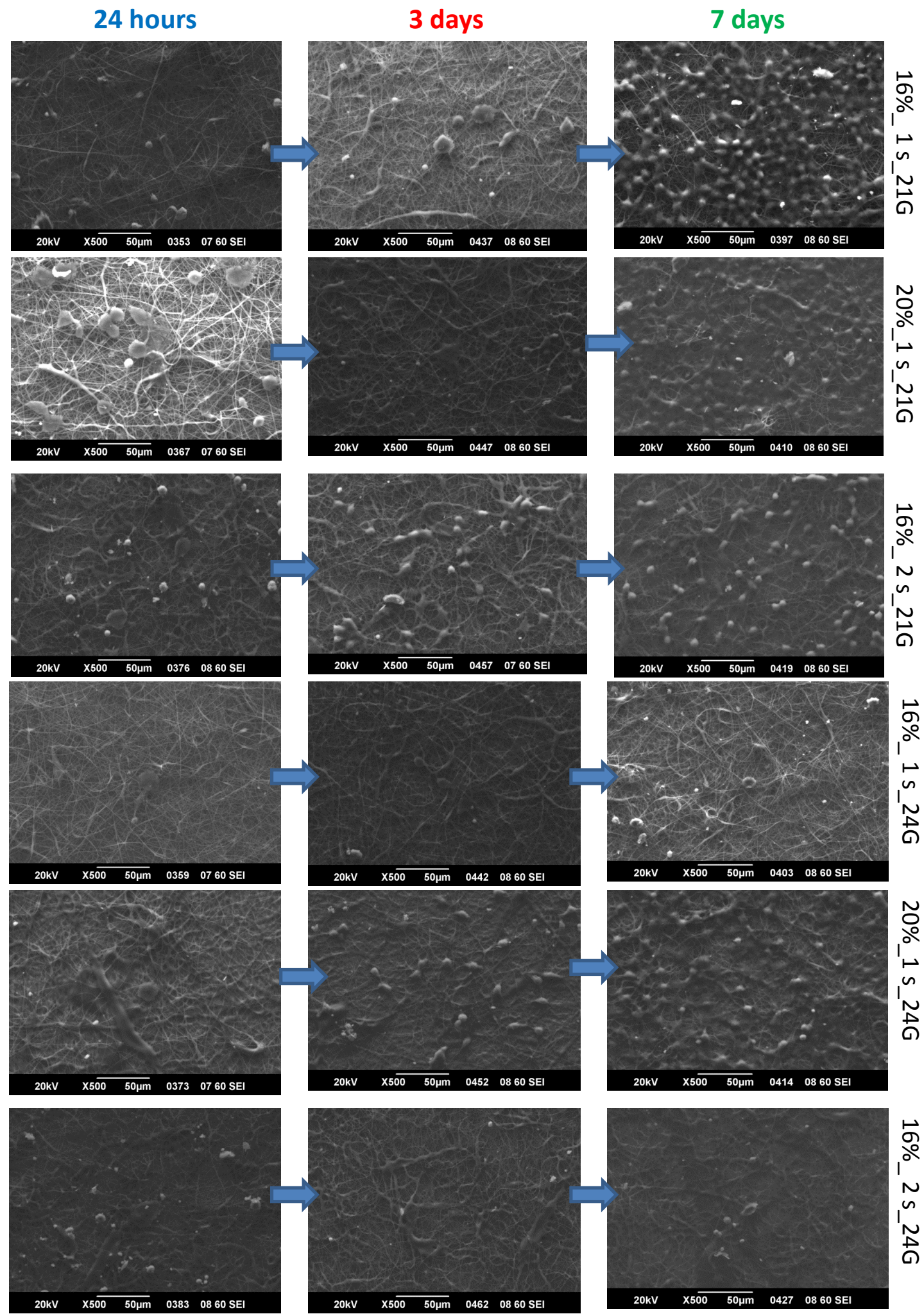

Figure 6. Images with Scanning Electron Microscopy (SEM) after cultivation of the L929s cell line onto cellulose acetate scaffolds at intervals 24 h, 3 days and 1 week. Solvents:Acetone/DMAc 2:1, Substrate: al. foil. Zoom: $\times 500 \mathrm{~mm}$ 
According to findings from Indirect MTT assay (Figure 7). The higher cell viability presenting all the samples from 3 and 7 days extracts while the smaller cell viability, presenting all the samples of 45 and 60 days extracts. The samples with $20 \% \mathrm{w} / \mathrm{v}$ concentration in both two groups of needles, indicate the expected behavior of the viability of fibroblasts, where in the largest duration extract seems to have less viability, but always comparable to the control. The 14 days extracts in all samples show a decrease in the viability of fibroblasts. In samples with 2 syringes, the unevenness of the scaffolds is visible because of the results in the diagram.

\subsection{Biofunctionalization}

In biofunctionalization, the sample which was selected $20 \% \mathrm{w} / \mathrm{v}$ CA concentration, produced by the $24 \mathrm{G}$ needle with 1 syringe, substrate: al. foil, as the sample was found to exhibit good physicochemical, morphological and non-cytotoxic properties for heart valve application. Also the sample $16 \% \mathrm{w} / \mathrm{v}$ CA concentration, produced by the $24 \mathrm{G}$ needle with 2 syringes was chosen as control sample, because it does not show properties which make it preferable for cell growth. On the surface of the CA fibers, molecules operatively linked such as RGD (Arg-Gly-Asp) peptide and YIGSRG laminins. These molecules are recognized by molecules of ECM and thus the scaffold becomes more compatible for the cells so as to bind and develop onto fibers. It was found that the images from SEM and Methylene blue dye/Optical microscope that biofunctionalized CA-based scaffolds (Figure 8) exhibit higher in comparison with the unfunctionalized ones. The MTT test (Figure 9) confirm that the selected samples (20\%_1s_24G) showed maximum cell proliferation.

\subsection{Aortic Valve Surface Coated with Biofunctionalized CA Scaffold}

CA-based nanofibrous biofunctionalized scaffolds were deposited on the surface of the aortic heart valve leaflets made of pyrolytic carbon. From the SEM images it was found that cells were grown successfully on the valve surface (Figure 10). Cells in 24 hours

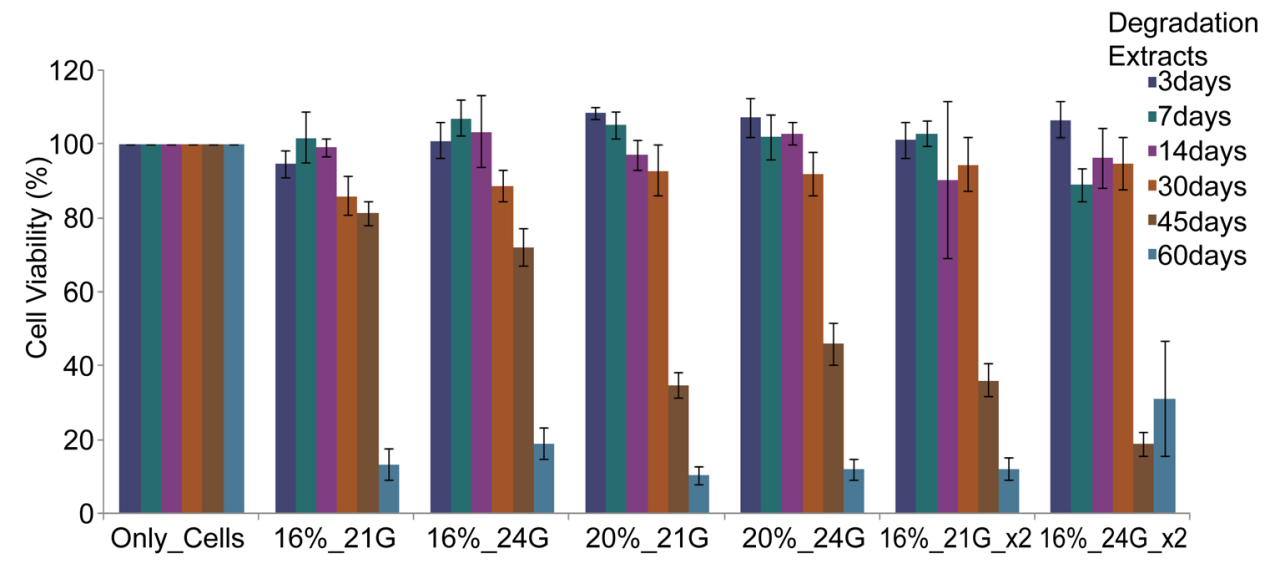

Figure 7. Diagram of (OD) Optical density at $570 \mathrm{~nm}$ (cell viability\%) after indirect MTT assay, using L929s cell line for at $24 \mathrm{~h}$. Solvents:Acetone/DMAc, 2:1. 
20\%_1s_24G w/o biofunctionalization
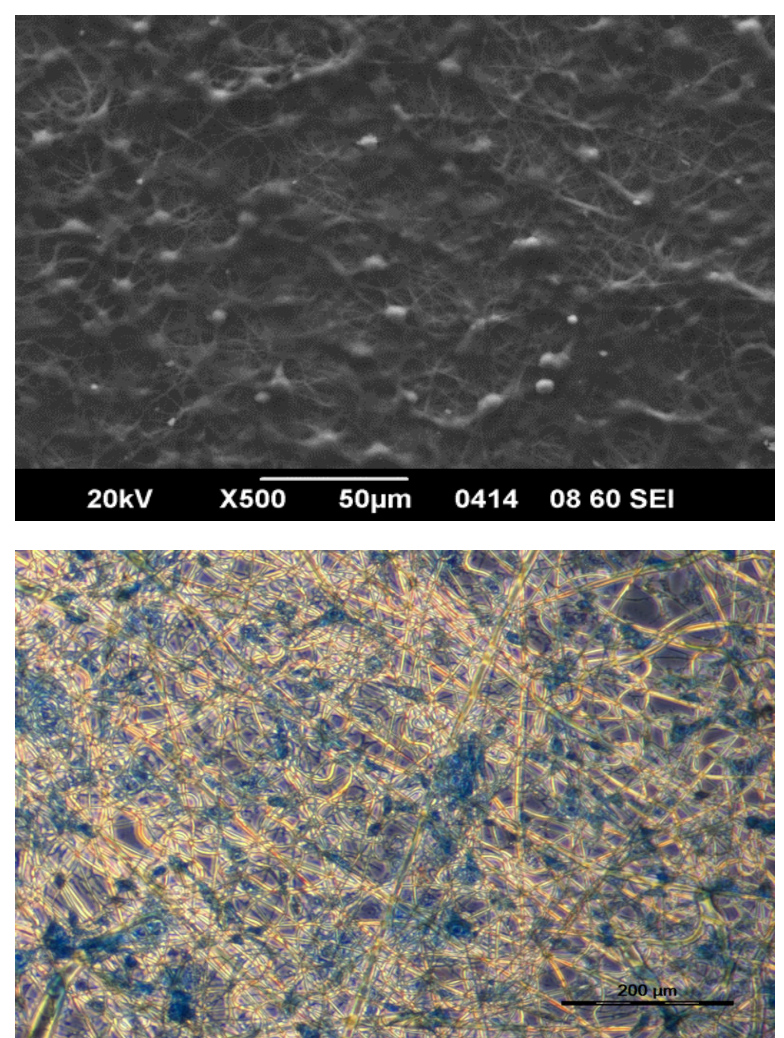

20\%_1s_24G biofunctionalized sample RGD peptide/Laminin

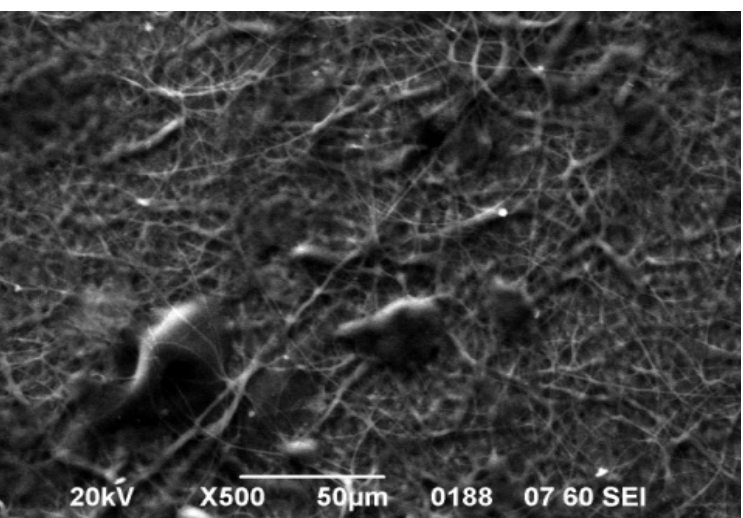

Figure 8. Top: Photos from Electron Microscopy (SEM) after cultivation L929s cell line onto cellulose acetate scaffolds in time 7 days. Substrate: al. foil. Below: Pictures from optical microscope after staining with methylene blue cultured cell L929s series onto cellulose acetate scaffolds. Substrate: glass. Sample: 20\%_1s_24G in Acetone/DMAc 2:1. Zoom SEM: $\times 500 \mathrm{~mm}$, magnification optical microscope: $200 \mathrm{~mm}$.

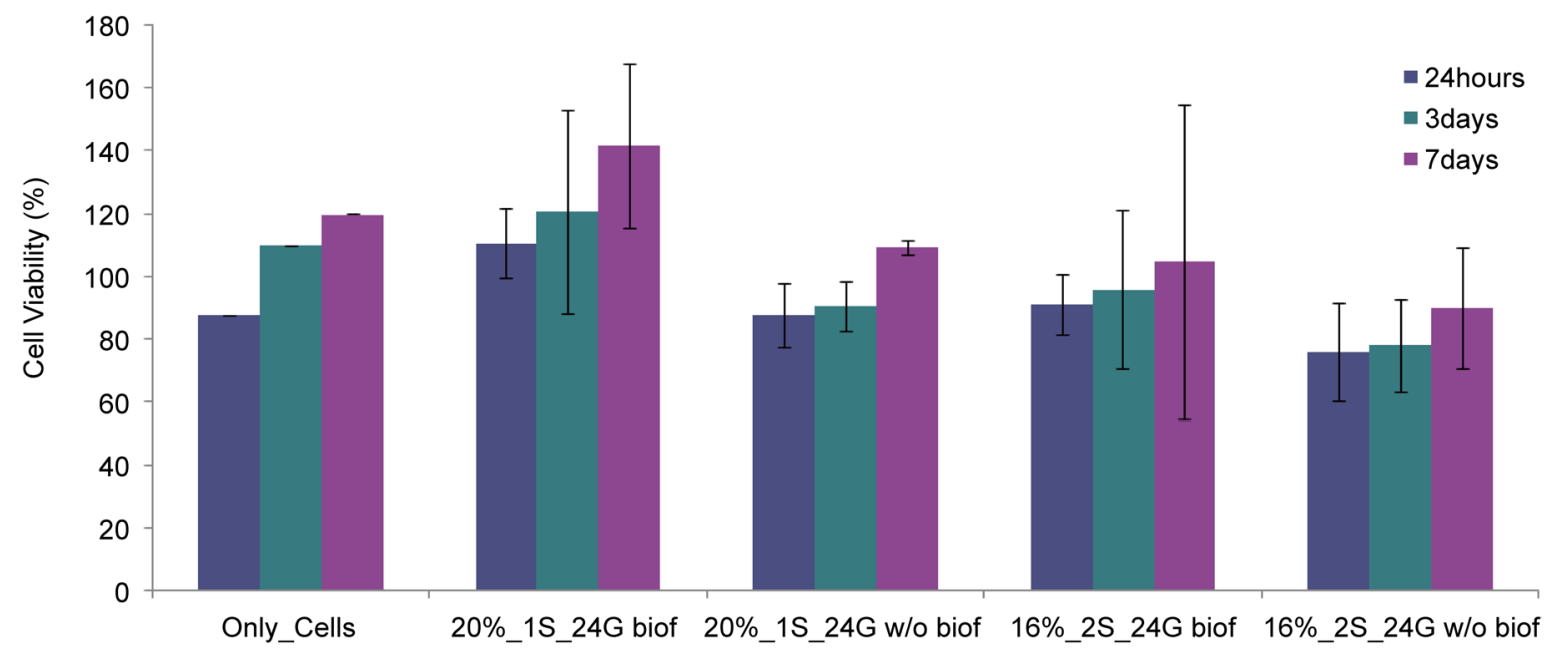

Figure 9. Diagram of Optical density (OD) at $560 \mathrm{~nm}$ after MTT assay L929s cells at time intervals $24 \mathrm{~h}, 3$ days and 7 days. Sample: $20 \% \_1$ s_24G and 16\%_2s_24G biofunctionalizated and 20\%_1s_24G and 16\%_2s_24G without (w/o) biofunctionalization. Solvents:Acetone/DMAc 2:1, substrate: al. foil. 

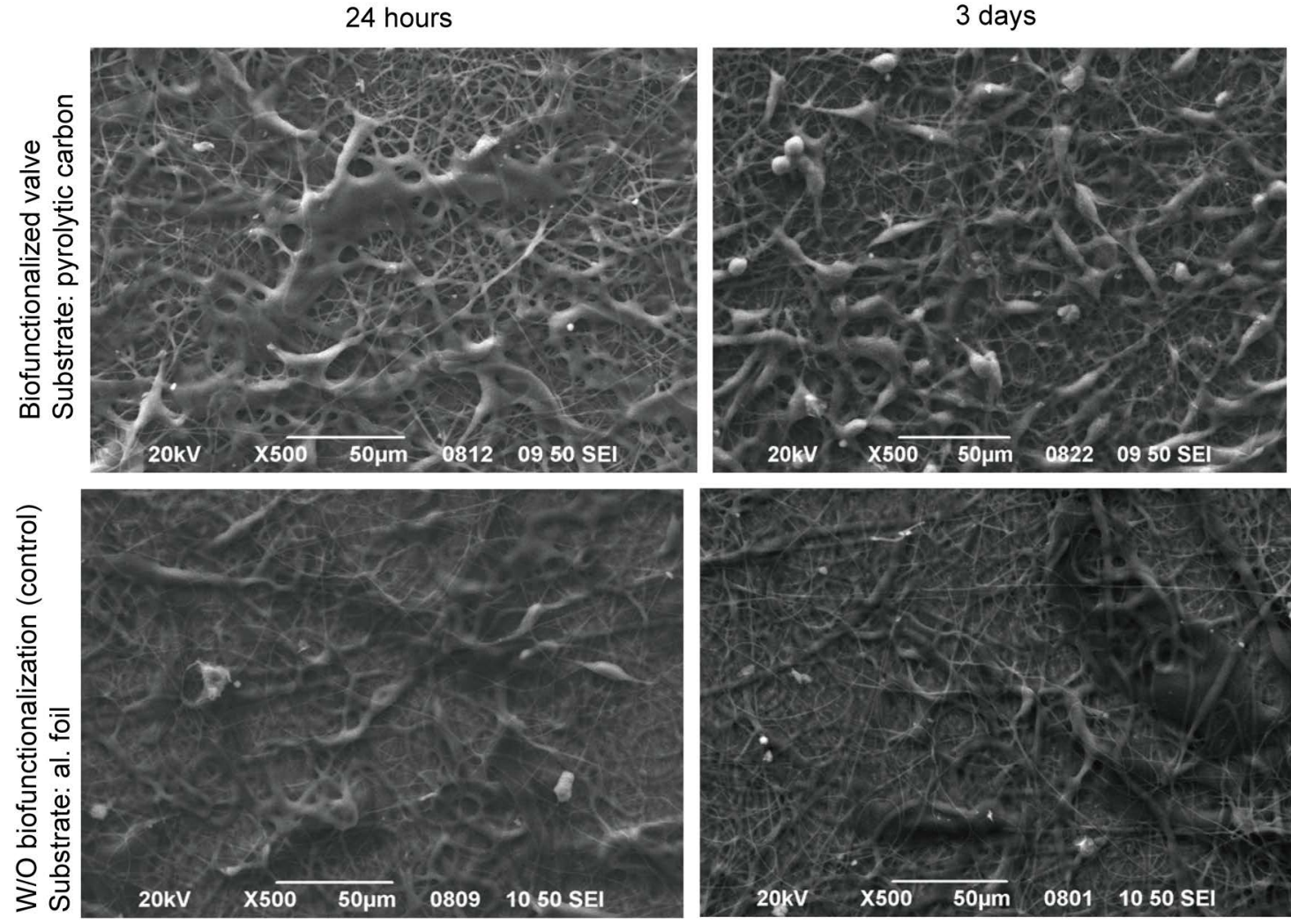

Figure 10. Electronic Microscopy (SEM) Images after cultivation, using L929s cell line onto biofunctionalized acetate scaffolds at $24 \mathrm{~h}$ and 3 days intervals. Sample: 20\%_1s_24G in Acetone/DMAc 2:1, substrate: pyrolytic carbon (aortic valve), and al. foil. Zoom: $\times 500 \mathrm{~mm}$.

start the multiplication and then 3 days increased sharply. Also, the growth of cells in biofunctionalized surface valve was higher as compared to the biofunctionalized sample with al. foil substrate both $24 \mathrm{~h}$ and in 3 days.

\section{Discussion}

In this study, we demonstrated that CA-based nanoscaffolds, which are deposited onto aortic heart valve leaflets promote cell growth. This was achieved through the study of the factors that affect cell adhesion onto cellulose acetate scaffolds surface, such as physicochemical and morphological properties of the polymer as well as testing their biodegradability behavior. It is known that the CA-bas scaffolds improve their integrity by blending with other polymers like PBA [poly (buty acrylate)] [25]. Additionally, an optimized scaffold which are used in tissue regeneration should consist of a dense network of interlocking fibers with uniform size distribution and minimal or no presence at all of beads. So, it is known [22] [30] that solvent selection along with flow rate and CA concentration strongly influenced the cellulose acetate fiber size, size distribution, and fiber geometry. As regards the acetone/DMAc system, residual DMAc was retained within the electrospun mat. This retention helped to create physical crosslinks between fibers for the electrospun mats allowing the preservation of structure after the regenera- 
tion process. In this study we demonstrated how additional parameters such as, needle size, number of syringes and CA concentration can influence the CA fiber size, size distribution, and fiber geometry and therefore topography, roughness, wettability and biodegradability. We observed that (Table 1) scaffolds with 24 g needle size, 1 syringe and $16 \% \mathrm{w} / \mathrm{v}$ concentration create fibers with smaller diameter than those with $21 \mathrm{~g}$ needle size, 2 syringes and 20\% w/v concentration, respectively. The fibers of CA-based scaffolds were well-formed without any beads formation. By measuring the roughness of CA samples, it was found that the scaffolds which were prepared with two syringes exhibited the higher had roughness values while all other samples were ranged in intermediate values. Moreover, the wetting angle measurements showed that as the roughness of the CA scaffolds increases, their hydrophilicity increases as well. Specifically, the three samples that showed the higher roughness values are hydrophilic while the three samples which showed the lower roughness values are hydrophobic. Also, samples engineered with $24 \mathrm{G}$ needles exhibit smaller contact angle value in relation to the samples made by $21 \mathrm{G}$ needles. Hydrophobic samples tend to degrade more difficult as they show greater upheavals in their weight, and take longer to achieve a complete degradation (Figure 2). In contrast, the hydrophilic samples showed lower rate of degradation. Also from the samples with $20 \% \mathrm{w} / \mathrm{v} \mathrm{CA}$, which are both hydrophilic, the scaffold with $24 \mathrm{G}$ degrades faster over 2 months in relation to the scaffold with $21 \mathrm{G}$, as it exhibits a higher hydrophilicity (Figure 2(c)). So far, in other studies, degradation of cellulose acetate fibers have achieved by using either the cellulase (cytocompatible enzyme) [16] or by using $\mathrm{KOH} /$ ethanol [31] for hydrolysis of fibers. The CA degradation produces acetyl groups and $\mathrm{OH}^{-}$. In this study, the deacetylation of CA fibers was carried out with the cell's medium. A reduce in fiber's diameter was observed as the days went on. In MTT direct assay, the time intervals 24 hours, 3 days and 7 days were selected as the most appropriate to study the behavior of cells on the surface of the scaffolds. More precisely, the $24 \mathrm{~h}$ provide information on the initial adhesion of cells, 3 days for the possibility of proliferation of cells and 7 days for the proliferation, organization and behavior of cells. We found that the cellulose acetate scaffolds are not toxic to cells. All samples showed cell growth but the sample 20\%_1s_24G showed the maximum cell proliferation and therefore the maximum biocompatibility. On the other hand, samples with 2 syringes showed less cell growth irrespective of the size of the needle and the concentration of CA, which is likely due to the complex structure of the fibers and hence the higher roughness values. The cells seem not to prefer such surfaces. Hydrophilic samples show intense cell growth but not the sample with 2 syringes, this probably occurs due to the high roughness value. Hydrophobic samples do not show so intense cell proliferation compared to the hydrophilic. Additional data we got from indirect MTT assay. It was found that increasing the concentration of CA causes a decrease in cell viability. This result represents a further confirmation that the cellulose acetate fibers are degraded. The sample 20\%_1s_24G was found to have roughness compared with the other samples as well as it is hydrophilic, biodegradable and shows the maximum cell growth. Subsequently this sample was applied in heart valve surface, 
as it adequately seems to perform the physicochemical and morphological properties.

It is well known that the activity of cell-adhesive proteins can be markedly affected by the surface chemistry [32] [33] [34] [35]. The surface of CA-based scaffolds was reinforced with RGD (Arg-Gly-Asp) peptides and YIGSRG laminins in order to mimic better the ECM and as an aftereffect to increase biocompatibility. Indeed toxicity results which came from direct MTT assay in line the observation studies of cells by SEM images and Methylene blue staining confirmed this embodiment as they showed increased cell proliferation in biofunctionalized scaffolds compared with those who had no active molecules on their surface. On the one hand, the biofunctionalized surfaces have replaced their free hydroxy groups with amino groups and then with RGD peptides and laminins, which easily allows the contact with the cell's integrins. This happens not only because the negative charge has been replaced but also because there are already RGD peptides and laminins which are easily accessible to connect with integrins of the cells. RGD functionalized biomaterials stimulate different cell responses not only by different average surface concentrations of ligands but also by presenting the ligands in a way that allow or even trigger integrin aggregation [36] [37]. Additionally, it is known that the changes in the activity of cell-adhesive proteins are often attributed to different protein conformation induced by different surface wettability. More extended conformation and enhanced activities of cell-adhesive proteins are observed on hydrophilic surfaces than on hydrophobic surfaces. In our experiment we use two hydrophilic samples, which are differentiated in CA concentration and number of syringes there were used. So, as it is known the fact that the factors which greatly affect the absorption of fibronectin (FN) are the surface chemistry and functional groups, wetting, roughness and topography, we conclude that because the samples are both hydrophilic but differ strongly in the values of roughness as the scaffold with $20 \%$ concentration- 1 syringe has less roughness compared to sample with $16 \%$ concentration- 2 syringes, therefore hydrophilic CA surfaces with a mean value of roughness and small diameter of fibers, is preferable from the cells. In the last step of experiments, CA-based biofunctionalized scaffolds were deposited on the surface of the aortic heart valve leaflets made of pyrolytic carbon by electrospinning. From the SEM images it was found that cells grown on the surface of the valve successfully. The growth of cells on the biofunctionalized CA valve surface is stronger than the one bare on both $24 \mathrm{~h}$ and in 3 days. The results are promising as the cells successfully grown on the nanofibrous CA-based surface of the aortic valve and enhance the prospect of creating an artificial valve which simulates the characteristics of a natural valve. In this way tissue regenerated heart valves will perfectly simulate the external environment of the cell while avoiding adverse side effects of surgery and a lifetime pharmaceutical anticoagulation.

\section{Conclusion}

In summary, we have successfully performed the development and characterization of the physicochemical and morphological properties of cellulose-acetate-based nanoscaffolds and the subsequent use of them as coverings onto aortic heart valve surface in 
order to attempt creation of an artificial valve that simulates the properties of a native valve. Bioactive factors, such as RGD peptides and laminins not only make the valve's surface more biocompatible but also could provide controlled endothyliazation and therefore a reduction in valve thrombosis. In this way, if we manage to combine the advantages of artificial valves with those of biological ones, it is almost sure that in the future we will have more efficient valves, which will not generate thrombosis after admission the patient's body and so the patient would not need anticoagulation for a lifetime. Although modest progress has been made toward the goal of a clinically useful tissue engineered heart valve, further success and ultimate human benefit will be dependent upon advances in biodegradable scaffolds, cellular manipulation and biofunctionalization strategies for rebuilding the native cardiac tissues.

\section{Acknowledgements}

This work has received funding from the European Union's Horizon 2020 research and innovation programme under grant agreement 646221, NanoReg II project.

\section{References}

[1] Filova, E., Straka, F., Mirejovsky, T., Masin, J. and Bacakova L. (2009) Tissue-Engineered Heart Valves. Physiological Research, 58, S141-S158. http://www.biomed.cas.cz/physiolres/pdf/58\%20Suppl\%202/58_S141.pdf

[2] Yacoub, M.H. and Takkenberg, J.J. (2005) Will Heart Valve Tissue Engineering Change the World? Nature Clinical Practice Cardiovascular Medicine, 2, 60-61. http://dx.doi.org/10.1038/ncpcardio0112

[3] Karagkiozaki, V. (2013) Nanomedicine Highlights in Atherosclerosis. Journal of Nanoparticle Research, 15, 1529. http://link.springer.com/article/10.1007/s11051-013-1529-1 http://dx.doi.org/10.1007/s11051-013-1529-1

[4] Medtronic Inc (2000) News Release: Medtronic Receives CE Mark, Releases New Mechanical Heart Valve to European Surgeons. Medtronic Inc., Minneapolis. http://www.medtronic.com/us-en/about/news.html

[5] American Heart Association (2004) Heart and Stroke Statistical Update. Dallas. http://www.heart.org/HEARTORG/General/Heart-and-Stroke-Association-Statistics_UCM 319064_SubHomePage.jsp

[6] Vesely, I. (2005) Heart Valve Tissue Engineering. Circulation Research, 97, 743-755. http://circres.ahajournals.org/content/97/8/743.short http://dx.doi.org/10.1161/01.RES.0000185326.04010.9f

[7] Schoen, F.J. and Levy, R.J. (1999) Tissue Heart Valves: Current Challenges and Future Research Perspectives. Journal of Biomedical Materials Research, 47, 439-465.

http://www.ncbi.nlm.nih.gov/pubmed/10497280 http://dx.doi.org/10.1002/(SICI)1097-4636(19991215)47:4<439::AID-JBM1>3.0.CO;2-O

[8] Stelt, B.J. Tissue Engineering of Aortic Valves, BMTE 04.23. A Literature Review, Eindhoven University of Technology Faculty of Biomedical Engineering. http://www.mate.tue.nl/mate/pdfs/4335.pdf

[9] Rahimtoola, S. (2003) Choice of Prosthetic Heart Valve for Adult Patients. Journal of the American College of Cardiology, 41, 893-904.

http://www.sciencedirect.com/science/article/pii/S0735109702029650 
http://dx.doi.org/10.1016/S0735-1097(02)02965-0

[10] Hammermeister, K., Sethi, G.K., Henderson, W.G., Grover, F.L., Oprian, C. and Rahimtoola, S.H. (2000) Outcomes 15 Years after Valve Replacement with a Mechanical versus a Bioprosthetic Valve: Final Report of the Veterans Affairs Randomized Trial. Journal of the American College of Cardiology, 36, 1152-1158.

http://www.sciencedirect.com/science/article/pii/S0735109700008342

http://dx.doi.org/10.1016/S0735-1097(00)00834-2

[11] Jamieson, W.R., von Lipinski, O., Miyagishima, R.T., Burr, L.H., Janusz, M.T., Ling, H., Fradet, G.J., Chan, F. and Germann, E. (2005) Performance of Bioprostheses and Mechanical Prostheses Assessed by Composites of Valve-Related Complications to 15 Years after Mitral Valve Replacement. Journal of Thoracic and Cardiovascular Surgery, 129, 13011308. http://www.jtcvsonline.org/article/S0022-5223(05)00010-3/abstract http://dx.doi.org/10.1016/j.jtcvs.2004.09.042

[12] Schoen, F.J. (2001) Pathology of Heart Valve Substitution with Mechanical and Tissue Prostheses. In: Silver, M.D., Gotlieb, A.I. and Schoen, F.J., Eds., Cardiovascular Pathology, 3rd Edition, Churchill Livingstone, New York, 629-677.

[13] Aschermann, M. (2004) Kardiologie. Galen, Prague, 1322. (In Czech)

[14] Concha, M., Aranda, P.J., Casares, J., Merino, C., Alados, P., Munoz, I., Gonzales, JR., Ribes, R. and Villalbar, R. (2004) The Ross Procedure. Journal of Cardiac Surgery, 19, 401409.

http://onlinelibrary.wiley.com/doi/10.1111/j.0886-0440.2004.04080.x/abstract;jsessionid=64 0ECCB9CEE30E68157430D9AE640DB9.f02t03 http://dx.doi.org/10.1111/j.0886-0440.2004.04080.x

[15] Malm, C. and Tanghe, L. (1955) Chemical Reactions in the Making of Cellulose Acetate. Industrial \& Engineering Chemistry, 47, 995-999.

http://pubs.acs.org/doi/abs/10.1021/ie50545a034 http://dx.doi.org/10.1021/ie50545a034

[16] Entcheva, E., Bien, H., Yin, L., Chung, C.Y., Farrell, M. and Kostov, Y. (2004) Functional Cardiac Cell Constructs on Cellulose-Based Scaffolding. Biomaterials, 25, 5753-5762.

http://www.sciencedirect.com/science/article/pii/S0142961204000699 http://dx.doi.org/10.1016/j.biomaterials.2004.01.024

[17] Chronakis, J. (2005) Novel Nanocomposites and Nanoceramics Based on Polymer Nanofibers Using Electrospinning Process-A Review. Journal of Materials Processing Technology, 167, 283-293.

http://citeseerx.ist.psu.edu/viewdoc/download?doi=10.1.1.454.7484\&rep=rep1\&type=pdf http://dx.doi.org/10.1016/j.jmatprotec.2005.06.053

[18] Nandakumar, A., Tahmasebi Birgani, Z., Santos, D., Mentink, A., Auffermann, N., van der Werf, K., Bennink, M., Moroni, L., van Blitterswijk, C. and Habibovic, P. (2013) Surface Modification of Electrospun Fibre Meshes by Oxygen Plasma for Bone Regeneration. Biofabrication, 5, Article ID: 015006.

http://iopscience.iop.org/article/10.1088/1758-5082/5/1/015006/meta;jsessionid=39E95CA3 EC5EF61CD9C6ABD537C6166F.c1.iopscience.cld.iop.org http://dx.doi.org/10.1088/1758-5082/5/1/015006

[19] Chen, J-P. and Su, C.-H. (2011) Surface Modification of Electrospun PLLA Nanofibers by Plasma Treatment and Cationized Gelatin Immobilization for Cartilage Tissue Engineering. Acta Biomaterialia, 7, 234-243.

https://www.researchgate.net/publication/45799053_Surface_modification_of_electrospun_ PLLA_nanofibers_by_plasma_treatment_and_cationized_gelatin_immobilization_for_carti 
lage_tissue_engineering

http://dx.doi.org/10.1016/j.actbio.2010.08.015

[20] Pappa, A.-M., Karagkiozaki, V., Krol, S., Kassavetis, S., Konstantinou D., Pitsalidis, C., Tzounis, L., Pliatsikas, N. and Logothetidis, S. (2015) Oxygen-Plasma-Modified Biomimetic Nanofibrous Scaffolds for Enhanced Compatibility of Cardiovascular Implants. Beilstein Journal of Nanotechnology, 6, 254-262.

http://www.beilstein-journals.org/bjnano/single/articleFullText.htm?publicId=2190-4286-6 $-24$

http://dx.doi.org/10.3762/bjnano.6.24

[21] Ramakrishna, S., Fujihara, K., Teo, W.-E., Yong, T., Ma, Z. and Ramaseshan, R. (2006) Electrospum Nanofibres: Solving Global Issues. Materialstoday, 9, 40-50. http://www.sciencedirect.com/science/article/pii/S136970210671389X http://dx.doi.org/10.1016/S1369-7021(06)71389-X

[22] Rodriguez, K., Gatenholm, P. and Renneckar, S. (2012) Electrospinning Cellulosic Nanofibers for Biomedical Applications: Structure and in Vitro Biocompatibility, Cellulose, 19, 1583-1598. http://link.springer.com/article/10.1007/s10570-012-9734-0 http://dx.doi.org/10.1007/s10570-012-9734-0

[23] Wang, Y., Robertson, J., Spillman Jr., W. and Claus, R. (2004) Effects of the Chemical Structure and the Surface Properties of Polymeric Biomaterials on Their Biocompatibility. Pharmaceutical Research, 21, 1362-1373. http://link.springer.com/article/10.1023/B:PHAM.0000036909.41843.18 http://dx.doi.org/10.1023/B:PHAM.0000036909.41843.18

[24] Rocktotpal, K., Niranjan, K. and Manjusri, M. (2013) Electrospun Cellulose Acetate Nanofibers: The Present Status and Gamut of Biotechnological Applications. Biotechnology Advances, 31, 421-437.

https://www.researchgate.net/publication/234107090_Electrospun_cellulose_acetate_nanofi bers_The_present_status_and_gamut_of_biotechnological_applications http://dx.doi.org/10.1016/j.biotechadv.2013.01.002

[25] Baek, W.-I., Pant, H.-R., Nam, K.-T., Nirmala, R., Oh, H.-J., Kim, I. and Kim, H.-Y. (2011) Effect of Adhesive on the Morphology and Mechanical Properties of Electrospun Fibrous Mat of Cellulose Acetate. Carbohydrate Research, 346, 1956-1961.

http://www.sciencedirect.com/science/article/pii/S0008621511002874 http://dx.doi.org/10.1016/j.carres.2011.05.025

[26] Wise, S., Waterhouse, A., Kondyurin, A., Bilek, M. and Weiss, A. (2012) Plasma-Based Biofunctionalization of Vascular Implants. Nanomedicine, 7, 1907-1916.

http://www.futuremedicine.com/doi/abs/10.2217/nnm.12.161?url_ver=Z39.88-2003\&rfr_id =ori:rid:crossref.org\&rfr_dat $=$ cr_pub\%3dpubmed http://dx.doi.org/10.2217/nnm.12.161

[27] Guo, L.M., Zeng, X.F., Ma, R.D., Shang, G.S., Hao, M. and Yi, D.H. (2010) [Surface Modification of RGD Peptides onto Acellularized Porcine Aortic Valve to Promote Cell Adhesion]. Journal of Sichuan University (Medical Science Edition), 41, 1008-1011, 1054.

http://www.pubpdf.com/pub/21265104/Surface-modification-of-RGD-peptides-onto-acellu larized-porcine-aortic-valve-to-promote-cell-adhesio

[28] Domingos, M., Intranuovo, F., Gloria, A., Gristina, R., Ambrosio, L., Bártolo, P.J. and Favia, P. (2013) Improved Osteoblast Cell Affinity on Plasma-Modified 3-D Extruded PCL Scaffolds. Acta Biomaterialia, 9, 5997-6005.

https://www.researchgate.net/publication/234122267_Improved_osteoblast_cell_affinity_o n_plasma-modified_3-D_extruded_PCL_scaffolds http://dx.doi.org/10.1016/j.actbio.2012.12.031 
[29] Groll, J., Amirgoulova, E.V., Ameringer, T., Heyes, C.D., Rocker, C., Nienhaus, G.U. and Moller, M. (2004) Biofunctionalization, Ultrathin Coatings of Cross-Linked Star Shaped Poly (Ethylene Oxide) Allow Reversible Folding of Immobilized Proteins. Journal of the American Chemical Society, 126, 4234-4239. http://pubs.acs.org/doi/abs/10.1021/ja0318028 http://dx.doi.org/10.1021/ja0318028

[30] Tungprapa, S., Puangparn, T., Weerasombut, M., Jangchud, I., Fakum, P., Semongkhol, S., Meechaisue, C. and Supaphol, P. (2007) Electrospun Cellulose Acetate Fibers: Effect of Solvent System on Morphology and Fiber Diameter. Cellulose, 14, 563-575.

http://link.springer.com/article/10.1007/s10570-007-9113-4 http://dx.doi.org/10.1007/s10570-007-9113-4

[31] Son, W.-K., Youk, J.I.-H., Lee, T.-S. and Park, W.-H. (2004) Electrospinning of Ultrafine Cellulose Acetate Fibers: Studies of a New Solvent System and Deacetylation of Ultrafine Cellulose Acetate Fibers. Journal of Polymer Science Part B: Polymer Physics, 42, 5-11. http://onlinelibrary.wiley.com/doi/10.1002/polb.10668/abstract http://dx.doi.org/10.1002/polb.10668

[32] Cutler, S. and Garcia, A. (2003) Engineering Cell Adhesive Surfaces That Direct Integrin $\alpha_{5} \beta_{1}$ Binding Using a Recombinant Fragment of Fibronectin. Biomaterials, 24, 1759-1770. http://www.sciencedirect.com/science/article/pii/S0142961202005707 http://dx.doi.org/10.1016/S0142-9612(02)00570-7

[33] Garcia, A., Vega, M. and Boettiger, D. (1999) Modulation of Cell Proliferation and difFerentiation through Substrate-Dependent Changes in Fibronectin Conformation. Molecular Biology of the Cell, 10, 785-789. https://www.ncbi.nlm.nih.gov/pmc/articles/PMC25202/ http://dx.doi.org/10.1091/mbc.10.3.785

[34] Keselowsky, B., Collard, D. and Garcia, A. (2003) Surface Chemistry Modulates Fibronectin Conformation and Directs Integrin Binding and Specificity to Control Cell Adhesion. Journal of Biomedical Materials Research, 66A, 247-259.

http://onlinelibrary.wiley.com/doi/10.1002/jbm.a.10537/abstract http://dx.doi.org/10.1002/jbm.a.10537

[35] Miller, T. and Boettiger, D. (2003) Control of Intracellular Signaling by Modulation of Fibronectin Conformation at the Cell-Materials Interface. Langmuir, 19, 1723-1729. http://pubs.acs.org/doi/abs/10.1021/la0261500 http://dx.doi.org/10.1021/la0261500

[36] Irvine, D.J., Hue, K.A., Mayes, A.M. and Griffith, L.G. (2002) Simulations of Cell-Surface Integrin Binding to Nanoscale-Clustered Adhesion Ligands. Biophysical Journal, 82, 120 132. http://www.cell.com/biophysj/abstract/S0006-3495(02)75379-4 http://dx.doi.org/10.1016/S0006-3495(02)75379-4

[37] Hersel, U., Dahmen, C. and Kessler, H. (2003) RGD Modified Polymers: Biomaterials for Stimulated Cell Adhesion and Beyond. Biomaterials, 24, 4385-4415. http://www.sciencedirect.com/science/article/pii/S0142961203003430 http://dx.doi.org/10.1016/S0142-9612(03)00343-0 
Submit or recommend next manuscript to SCIRP and we will provide best service for you:

Accepting pre-submission inquiries through Email, Facebook, LinkedIn, Twitter, etc. A wide selection of journals (inclusive of 9 subjects, more than 200 journals)

Providing 24-hour high-quality service

User-friendly online submission system

Fair and swift peer-review system

Efficient typesetting and proofreading procedure

Display of the result of downloads and visits, as well as the number of cited articles

Maximum dissemination of your research work

Submit your manuscript at: http://papersubmission.scirp.org/

Or contact wjnse@scirp.org 